\title{
LIFE-HISTORY EVOLUTION AND THE POLYPHENIC REGULATION OF SOMATIC MAINTENANCE AND SURVIVAL
}

\author{
ThOMAS FlatT* \\ Institut für Populationsgenetik, Vetmeduni Vienna, A-1210 Vienna, Austria and Wissenschaftskolleg zu
}

Berlin, 14193 Berlin, Germany

E-MAIL: THOMAS.FLATT@UNIL.CH

\section{GRO V. AMDAM}

School of Life Sciences, Arizona State University, Tempe, Arizona 85287-4501 USA and Department of Chemistry, Biotechnology and Food Science, Norwegian University of Life Sciences, N-1432 Ås, Norway

E-MAIL: GRO.AMDAM@ASU.EDU

\section{ThOMAS B. L. KiRKWOOD}

Institute for Ageing and Health, Newcastle University, Newcastle upon Tyne NE4 5PL United Kingdom E-MAIL:TOM.KIRKWOOD@NEWCASTLE.AC.UK

\section{Stig W. Omholt}

Centre for Ecological and Evolutionary Synthesis, Department of Biology, University of Oslo, N-0316 Oslo, Norway and Department of Biology, Centre for Biodiversity Dynamics, NTNU Norwegian University of Science and Technology, NO-7491 Trondheim, Norway

E-MAIL: STIG.OMHOLT@NTNU.NO

KEYWORDS

life history, polyphenism, somatic maintenance, survival, evolution of aging, disposable soma

ABSTRACT

Here we discuss life-history evolution from the perspective of adaptive phenotypic plasticity, with a focus on polyphenisms for somatic maintenance and survival. Polyphenisms are adaptive discrete alternative phenotypes that develop in response to changes in the environment. We suggest that dauer larval diapause and its associated adult phenotypes in the nematode (Caenorhabditis elegans), reproductive dormancy in the fruit fly (Drosophila melanogaster) and other insects, and the worker

*Present Address: Department of Ecology and Evolution, University of Lausanne, CH-1015 Lausanne, Switzerland

The Quarterly Review of Biology, September 2013, Vol. 88, No. 3

Copyright (C) 2013 by The University of Chicago Press. All rights reserved.

0033-5770/2013/8803-0002\$15.00 
castes of the honey bee (Apis mellifera) are examples of what may be viewed as the polyphenic regulation of somatic maintenance and survival. In these and other cases, the same genotype can-depending upon its environment-express either of two alternative sets of life-history phenotypes that differ markedly with respect to somatic maintenance, survival ability, and thus life span. This plastic modulation of somatic maintenance and survival has traditionally been underappreciated by researchers working on aging and life history. We review the current evidence for such adaptive life-history switches and their molecular regulation and suggest that they are caused by temporally and/or spatially varying, stressful environments that impose diversifying selection, thereby favoring the evolution of plasticity of somatic maintenance and survival under strong regulatory control. By considering somatic maintenance and survivorship from the perspective of adaptive life-history switches, we may gain novel insights into the mechanisms and evolution of aging.

Adaptive Regulatory Plasticity of Somatic Maintenance and Survival

$\mathrm{R}$ ECENT progress in unraveling the molecular basis of aging suggests that somatic maintenance and life span are strongly influenced by evolutionarily conserved signaling pathways that respond to changes in the environment, for example, the nutrient sensing insulin/insulin-like growth factor signaling (IIS) and target of rapamycin (TOR) pathways (e.g., Tatar et al. 2003; Kenyon 2005; Partridge et al. 2005; Fielenbach and Antebi 2008; Kenyon 2010; Flatt and Heyland 2011). This raises the intriguing but rarely discussed possibility that such pathways have evolved to respond to environmental conditions in a way that allows organisms to plastically match their life history, and in particular their somatic maintenance and survival ability, with the prevailing environmental conditions (e.g., Shanley and Kirkwood 2000; Tatar and Yin 2001; Ackermann and Pletcher 2007; Fielenbach and Antebi 2008; Flatt and Schmidt 2009; Gerisch and Antebi 2011; Schaedel et al. 2012).

Somatic maintenance and survivorship matter evolutionarily only insofar as they enable or promote fitness (i.e., reproductive success, a function of both survival and reproductive effort). Under favorable conditions, individuals might opt to invest in reproduction at the cost of somatic maintenance and survival, while under suboptimal or stressful conditions they might plastically switch to a state of improved stress resistance, somatic maintenance, and survival until conditions for reproduction have become favorable again (e.g., Kirkwood 1977; Kirkwood and Rose 1991; Flatt 2011). Environmental heteroge- neity, and stressful conditions associated with such environmental variability, might thus select for the ability of organisms to sense the state of their environment and to plastically adjust their life history in response to these changes, thereby maintaining and optimizing fitness (e.g., Shanley and Kirkwood 2000; Ackermann and Pletcher 2007; Fielenbach and Antebi 2008; Flatt and Schmidt 2009; Gerisch and Antebi 2011). Traditionally, however, this adaptive plastic modulation of somatic maintenance and survival in response to the environment, and in particular its importance for making biologically sound inferences from experimental data, has not received much attention from biologists working on aging and longevity (but see Finch 1990; Finch and Rose 1995; Tatar and Yin 2001; Bateson et al. 2004; Flatt and Schmidt 2009). Here we discuss environmentally induced, alternative life-history phenotypes that differ markedly with respect to somatic maintenance, stress resistance, and survival ability and argue that they represent polyphenisms (also see Finch 1990; Finch and Rose 1995; Tatar and Yin 2001).

The term polyphenism, a form of phenotypic plasticity, denotes the ability of a genotype to produce two or more discrete alternative phenotypes in response to environmental stimuli or cues (e.g., Stearns 1989); it was introduced by Mayr (1963) to distinguish it from genetic polymorphism. Although polyphenism (sometimes also called "developmental switch," "adaptive switch," or "discrete plasticity") was originally meant to describe all kinds of phenotypic plasticity (Mayr 1963; also see Canfield and Greene 2009; Simpson et al. 2011), most current definitions are restricted to environmentally induced, discrete alternative pheno- 
types (e.g., Levins 1968; Shapiro 1976, 1984; Stearns 1989; West-Eberhard 1989, 2003; Moran 1992; Nijhout 2003; Beldade et al. 2011; but see discussion below). Well-known examples of polyphenisms include: the castes of ants, termites, bees, and wasps; the alternative seasonal color pattern and life-history morphs of some moths and butterflies; density-induced "phase polyphenisms" in armyworm moths, locusts, and grasshoppers; predator-induced helmet formation in water fleas; horn-length polyphenisms in male dung beetles; dispersalrelated wing formation polyphenisms in crickets, ants, aphids, and other insects; and heterophylly in some aquatic plants (e.g., Cook 1968; Nijhout and Wheeler 1982; Wheeler 1986; Nijhout 1994, 2003; Dingle and Winchell 1997; Tollrian and Harvell 1999; Emlen and Nijhout 2000; West-Eberhard 2003; Hunt and Amdam 2005; Braendle et al. 2006; Hunt et al. 2007; Simpson et al. 2011).

Traditionally, polyphenisms are best known for conspicuous morphological traits, but whether and how they affect life-history traits is in many cases unknown. Notable exceptions are, for example, the caste polyphenism in ants where queens are known to live substantially longer than workers (reviewed in Keller and Genoud 1997; Keller and Jemielity 2006); the seasonal polyphenism in the African squinting brown butterfly (Bicyclus anynana), where the dry- and wet-season forms not only differ in their wing patterns (uniform brown wings versus wings patterned with conspicuous eyespots) but also in several important life-history traits, including survival ability and stress resistance (e.g., reviewed in Brakefield and Zwaan 2011); and the wing polyphenism of aphids where the morphological differences between winged and wingless phenotypes are often correlated with differences in developmental time, length of the reproductive period, offspring production, and life span (reviewed in Braendle et al. 2006).

Here we focus on three specific cases of adaptive life-history switches that have dramatic qualitative and quantitative effects on survival ability and thus life span (e.g., Finch 1990; Finch and Rose 1995; Tatar and Yin 2001). The first and probably best-known example is dauer formation in Caenorhabditis elegans and other nematode worms. C. elegans and related species exhibit a facultative larval diapause elicited by stressful environmental conditions, the so-called dauer larva, a long-lived and stressresistant dispersal morph (e.g., Cassada and Russell 1975; Riddle and Albert 1997; Braendle et al. 2007; Félix and Braendle 2010). Importantly, many of the genes involved in C. elegans dauer formation are also implicated in the regulation of adult stress resistance and adult life span (e.g., Vanfleteren and Braeckman 1999; Rottiers and Antebi 2006; Fielenbach and Antebi 2008; Gerisch and Antebi 2011). A second, similar example, albeit restricted to the adult stage, is found in fruit flies of the genus Drosophila and other insects. In D. melanogaster, for example, low temperature and short day length trigger a state of reproductive dormancy characterized by ovarian arrest, increased stress resistance, and greatly improved survival (e.g., Saunders et al. 1989; Tatar and Yin 2001; Tatar et al. 2001a; Schmidt et al. 2005a,b; Schmidt and Paaby 2008). Nematode diapause and insect adult reproductive dormancy are cases of what has been called senescence plasticity, i.e., phenotypic plasticity affecting the rate of aging (e.g., Tatar and Yin 2001). A third striking example is provided by honey bees (Apis mellifera), where functionally sterile females that belong to the worker "helper" caste develop a stress-resistant and long-lived phenotype in the absence of colony reproduction, i.e., the production of new individuals and colonies from eggs laid by the queen (e.g., Amdam and Omholt 2002, 2003; Münch et al. 2008; Münch and Amdam 2010; Amdam 2011). Using these three cases as examples, we aim to illustrate how viewing somatic maintenance and survival from the perspective of adaptive life-history switches can inform our understanding of the mechanisms and evolution of aging.

Many other examples of life-history polyphenisms (and polymorphisms) with dramatic effects on adult survival and somatic maintenance could be given, for instance, from ants where-as mentioned abovegenetically identical individuals can differ in life span by several orders of magnitude (e.g., reviewed in Keller and Jemielty 2006), but discussing these cases is beyond the scope of this paper. Similarly, we do not 
discuss alternative reproductive strategies, even though these might be illuminating for our understanding of survival and maintenance polyphenisms; interesting examples include semelparous and iteroparous (albeit genetically determined, yet environmentally sensitive) life-history morphs in the ascidian Botryllus schlosseri, which differ dramatically in reproductive effort and life span (Grosberg 1988). We refer interested readers to the excellent monograph by Finch (1990) and the review by Taborsky and Brockmann (2010).

We begin by showing that the environmentally induced somatic maintenance and survival phenotypes in worms, flies, and bees meet the defining criteria of polyphenism. Second, we argue that such adaptive life-history switches may have been shaped by the same selection principle: the evolution of adaptive regulatory plasticity in somatic maintenance and survival is likely caused by temporally and/or spatially stressful environments that impose diversifying selection. Third, we ask whether this likely shared ultimate (evolutionary) basis of polyphenisms has resulted in similar proximate (mechanistic) solutions and find that the molecular regulatory principles that govern the expression of somatic maintenance and survival polyphenisms share many commonalities, especially at the endocrine level. Fourth, we discuss how accounting for plastic aspects of somatic maintenance and survival might affect the design and interpretation of experiments in molecular biogerontology. Finally, we address how polyphenisms in somatic maintenance and survival not only challenge aspects of the principal evolutionary theories of aging, but also how they can highlight important differences between them.

\section{Somatic Maintenance and Survival are Polyphenic in Worms, Flies, and BEES}

Polyphenisms are usually characterized by the following combination of features (e.g., see Levins 1968; Stearns 1976, 1982; Nijhout 2003): they are adaptive, discrete (but see below), environmentally induced, alternative phenotypes; they are produced in response to reliable and predictable token stimuli or cues from the environment; and their discrete alternative nature is either due to environmental discontinuity (e.g., discrete generations experiencing different seasons) or a discrete developmental switch in an environmentally sensitive threshold trait (e.g., triggered by critical photoperiod). Moreover, although perhaps not being a defining feature per se, polyphenic switches are typically centrally regulated by the neuroendocrine system, at least as far as is known (Nijhout 2003). In the following, we show that the plastic life histories of nematode worms, flies, and honey bees match these defining criteria and that they provide striking examples of adaptive somatic maintenance and survival polyphenisms (Figure 1).

Note, however, that the criterion that polyphenisms only refer to discrete (discontinuous) plastic traits is somewhat restrictive and artificial; typically this requirement can be relaxed without loss of generality (see Mayr 1963; Canfield and Greene 2009; Simpson et al. 2011). This is because the boundaries between cases of continuous phenotypic plasticity and discrete alternative morphs are often very blurry: for example, as discussed by Nijhout (2003), the butterfly Araschnia levana occurs in nature in two seasonal polyphenic morphs, a spring and a summer form. However, a whole range of intermediate forms can be produced by timed injections of the steroid hormone ecdysone, or by imposing intermediate environmental conditions in the laboratory (also see discussion in Canfield and Greene 2009). Also note that the original and more inclusive definition of polyphenism by Mayr (1963) encompasses cases of both discrete and continuous plasticity; thus, although the survival and maintenance polyphenism we discuss here can be said to involve qualitatively discrete phenotypic states, we follow Canfield and Greene (2009) and Simpson et al. (2011) by applying Mayr's more inclusive definition of polyphenism. Moreover, as pointed out by Simpson et al. (2011), it is very common that the same developmental hormones (or other regulatory mechanisms) are involved in different cases of discrete or continuous plasticity. Our current mechanistic knowledge therefore does not support the dichotomy between discrete versus continuous plasticity (Simpson et al. 2011). 


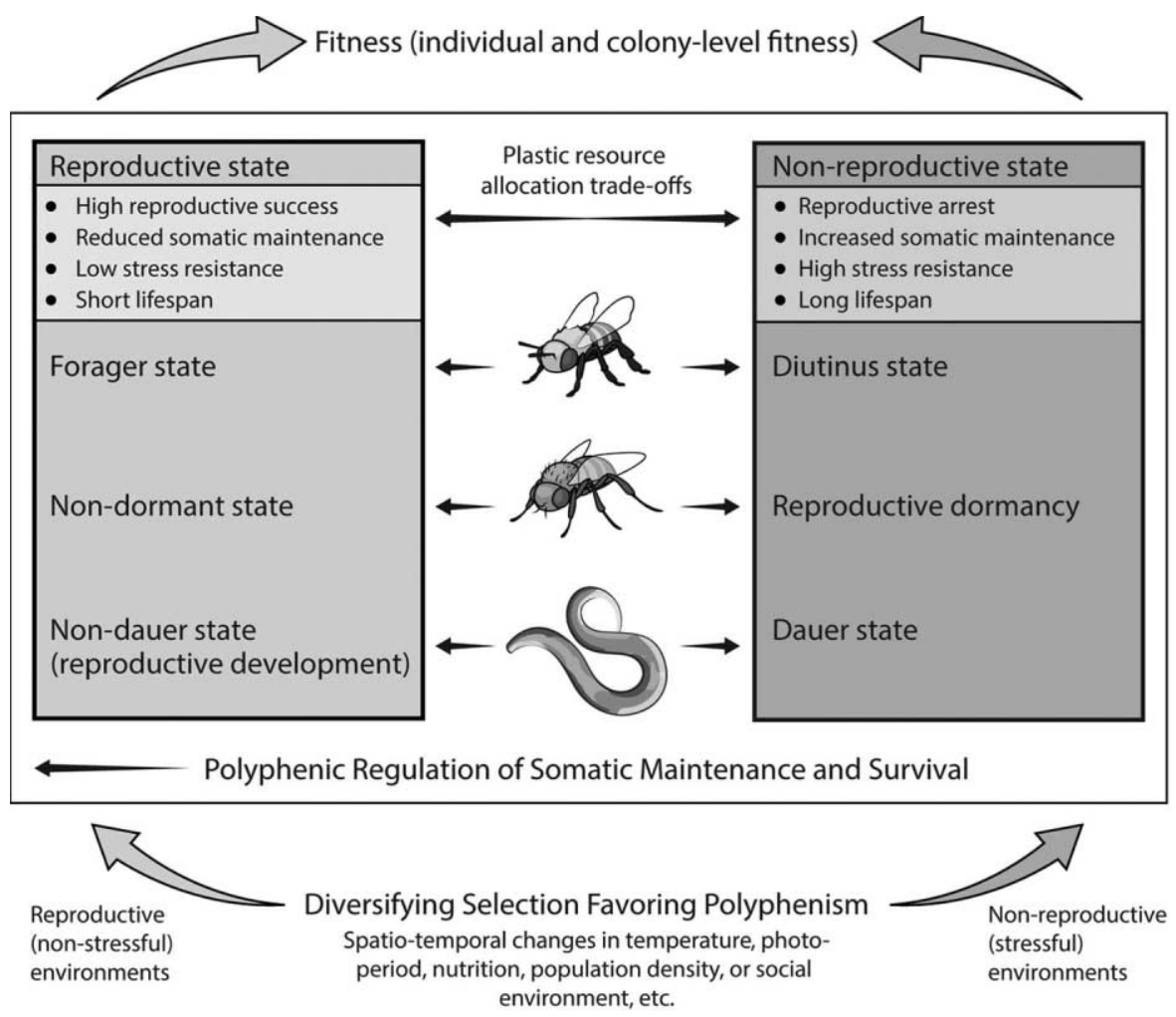

Figure 1. Maintenance and Survival Polyphenisms in Nematode Worms, Flies, and Bees

Dauer larval diapause and its associated adult phenotypes in the nematode ( $C$. elegans), reproductive dormancy in the fruit fly (D. melanogaster) and other insects, and the worker castes of the honey bee (Apis mellifera) represent examples of adaptive life-history polyphenisms for somatic maintenance and survival in response to stressful (nonreproductive) environments.

\section{DAUER DIAPAUSE IN C. ELEGANS}

Under normal environmental conditions, nematodes such as $C$. elegans develop from an embryo through four larval stages (L1 to L4) into reproductively mature adults in about $3.5-4$ days (at $20^{\circ} \mathrm{C}$; reproductive development). In contrast, under stressful conditions (e.g., crowding, starvation, high temperature), larvae arrest their development and alter their metabolism at the second molt (Figure 2). They bypass the normal L3 larval stage by forming a "dauer" larva (from the German word for "enduring"), an alternative stage that represents a facultative larval diapause, also called L3d (e.g., Cassada and Russell 1975; Riddle and Albert 1997; Braendle et al. 2007; Hu 2007; Fielenbach and Antebi 2008; Félix and Braendle
2010). The dauer, like other forms of diapause, represents a programmed state of arrested development and altered physiology that ensures somatic persistence and survival (e.g., Tatar and Yin 2001). In addition to dauer, C. elegans can also exhibit other less wellunderstood types of diapause or developmental and physiological arrest (e.g., Ruaud and Bessereau 2006; Padilla and Ladage 2012). For example, under starvation conditions at hatching, larvae undergo L1 diapause (Baugh and Sternberg 2006). These nondauer cases of developmental plasticity in C. elegans are, however, beyond the scope of our review.

It is easy to see how dauer larvae are somatically highly persistent: they have a hardened cuticle; do not feed (since they lack pharyngeal pumping) but use their fat reserves; are highly 


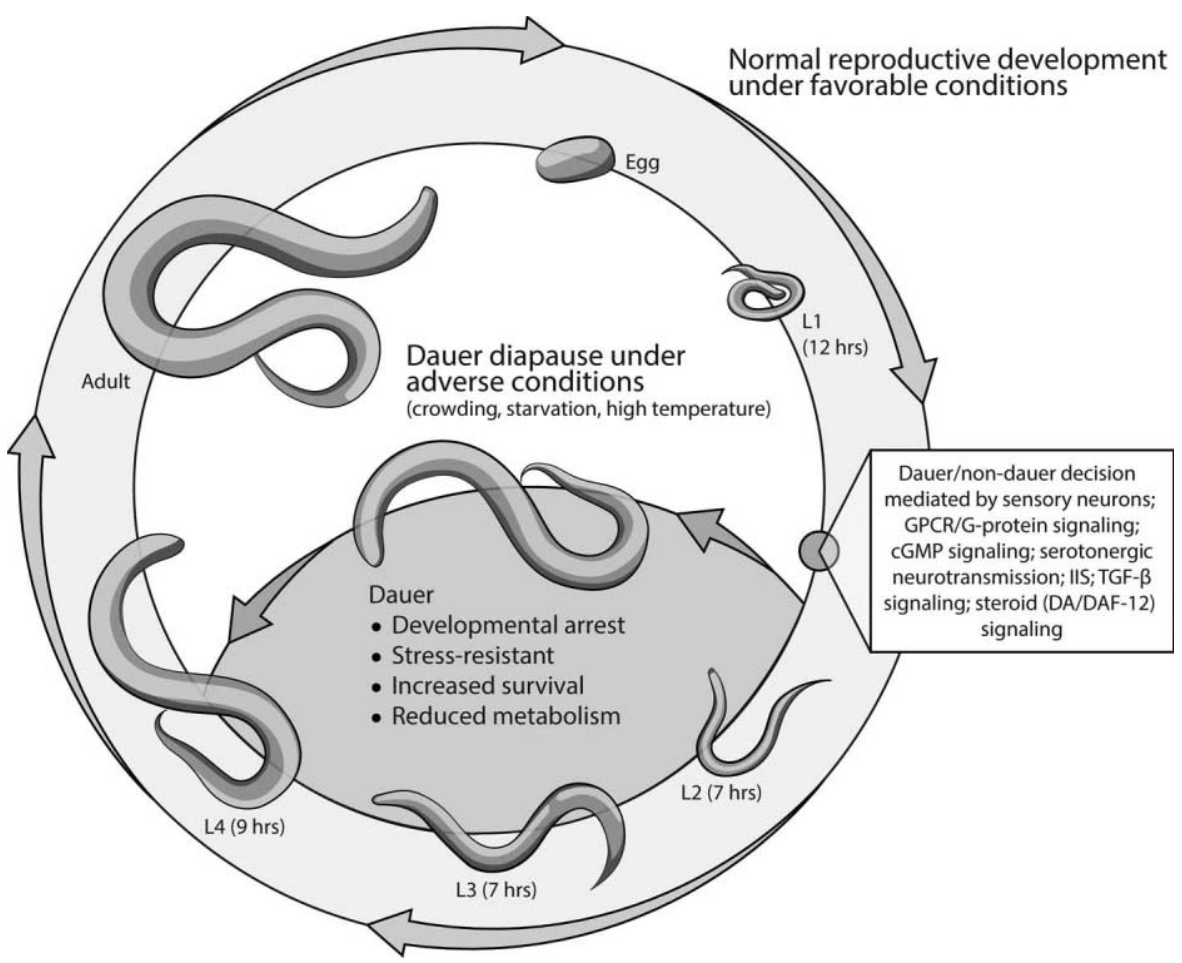

Figure 2. Dauer Diapause in Nematode Worms

In response to adverse environmental conditions (starvation, crowding, high temperature), nematode worms (C. elegans) can enter a stress-resistant and long-lived larval diapause stage called "dauer"; the "decision" to enter the dauer state is mediated by several molecular pathways, in particular, by different hormonal signaling pathways.

resistant to multiple stresses, including heat, oxygen deprivation, starvation, and oxidation; and can survive without food for three to six months (e.g., Cassada and Russell 1975; Klass and Hirsh 1976; Larsen 1993; Lithgow et al. 1995; Riddle and Albert 1997; Hu 2007; Fielenbach and Antebi 2008), or occasionally even up to 12 months (C. Braendle, pers. comm.). Whether dauer formation also protects against somatic DNA damage remains, to our knowledge, largely unknown; however, while dauer larvae are not more resistant than nondauer larvae to the life span-shortening effects of ionizing radiation (Johnson and Hartman 1988), the microRNA mir-34, which is strongly upregulated in the dauer stage, is known to be required for a robust DNA damage response (see Karp et al. 2011 and references therein).

The changes leading to dauer formation are accompanied by substantial alterations in metabolism, for example, involving a switch to glycolysis and fermentative metabolism (e.g., Vanfleteren and De Vreese 1995, 1996; Riddle and Albert 1997; Holt and Riddle 2003; Burnell et al. 2005; Fuchs et al. 2010). Once favorable conditions have returned, dauer larvae rapidly resume reproductive development, developing into postdauer L3/L4 larvae that, in turn, develop into reproductively mature adults with normal adult life span (Riddle and Albert 1997; Fielenbach and Antebi 2008).

The determinants of entry to the dauer state act at the L1 stage and depend on the interplay of three environmental cues: population density of conspecific individuals (i.e., crowding), food scarcity, and temperature (e.g., Golden and Riddle 1982, 1984a,b,c; Riddle and Albert 1997; Hu 2007). Crowding appears to be the primary cue triggering dauer formation and is 
mediated by several different small molecules that act as pheromones, called "ascarosides," which can induce dauer arrest while at the same time preventing dauer recovery (e.g., Golden and Riddle 1984c; Jeong et al. 2005; Butcher et al. 2007, 2008, 2009; Srinivasan et al. 2008; Gallo and Riddle 2009; Kim et al. 2009; Braendle 2012; Ludewig and Schroeder 2013). The effects of these prodauer pheromones are opposed by a "food cue," a heat-stable lipophilic molecule produced by bacteria, the food source of the nematodes, which inhibits dauer arrest and promotes dauer recovery (Golden and Riddle 1984b). The option to enter/exit the dauer depends on the ratio of these two cues and is further modulated by temperature (Golden and Riddle 1982, 1984a,b). At growth temperatures between $15^{\circ} \mathrm{C}$ and $25^{\circ} \mathrm{C}$, induction of dauer formation is moderate, whereas at $27^{\circ} \mathrm{C}$ induction is very strong and independent of the presence of prodauer pheromones (Ailion and Thomas 2000).

The phenomenon of dauer diapause is not only relevant for larval survival but also for survival and life span in the adult worm: many of the genes involved in C. elegans dauer formation (so-called daf genes; Riddle et al. 1981; Albert and Riddle 1988) are also implicated in the regulation of adult stress resistance and longevity (e.g., Vanfleteren and Braeckman 1999; Tatar and Yin 2001; Rottiers and Antebi 2006; Fielenbach and Antebi 2008; Gerisch and Antebi 2011). Different mutations in these genes have been classified as "dauer formation-defective" ( $d a f-d)$, i.e., mutants that always bypass "dauer" irrespective of environmental conditions, or as "dauer formation-constitutive" (daf-c), i.e., mutants that always enter dauer diapause (e.g., Riddle et al. 1981; Albert and Riddle 1988; Rottiers and Antebi 2006; Fielenbach and Antebi 2008). Interestingly, although dauer is a larval trait, certain weak $d a f-c$ mutant alleles of genes in the insulin/insulin-like growth factor signaling (IIS) or steroid hormone pathways (see below) allow the animals to bypass the larval dauer stage and to become stressresistant and long-lived adults (e.g., Kenyon et al. 1993; Larsen 1993; Lithgow et al. 1994; Dorman et al. 1995; Larsen et al. 1995; Gems et al. 1998; Rottiers and Antebi 2006; Fielenbach and Antebi 2008; Gerisch and Antebi 2011). Furthermore, dauer pheromone can extend adult life span in C. elegans (Kawano et al. 2005). The somatic persistence and slow aging that is characteristic of dauer diapause larvae can thus apparently also apply to the reproductive adult phase (Tatar and Yin 2001).

Dauer diapause clearly matches the above definition of an adaptive life-history polyphenism (also see Braendle et al. 2007). It is induced by defined environmental token cues and involves a switch between two adaptive, qualitatively discrete life-history "modes" (Figures 1 and 2). Moreover, the associated somatic maintenance and survival "program" can also extend to the adult stage. In addition, the dauer syndrome is under strong hormonal control (see below). Dauer diapause thus represents a clear example of the kind of adaptive somatic maintenance and survival polyphenisms that we have in mind (also see Tatar and Yin 2001). This being said, we are not aware of any study that has directly quantified the demographic fitness benefits and costs of the wild-type dauer versus nondauer life-history "strategy" under different environmental conditions.

\section{REPRODUCTIVE DORMANCY IN} D. MELANOGASTER

Many insects, including Drosophila, can exhibit a state of "dormancy." Dormancy is defined as an environmentally induced arrest of growth, development, and activity, accompanied by a downregulation of metabolic function, which may or may not be adaptive, but which enables somatic persistence over time (e.g., Danilevskii 1965; Tauber et al. 1986; Danks 1987; Tatar et al. 2001a; Koštál 2006; Schmidt 2011). Two basic types of dormancy can be distinguished, quiescence and diapause. In quiescence, the dormant state is a direct and immediate response to unfavorable aseasonal and/or unpredictable environmental conditions. Such a response may be facultative or inevitable and can be adaptive or not. In diapause, by contrast, the dormant state: is a profound physiological response to anticipatory token cues (e.g., temperature, photoperiod) in unfavorable (seasonally) predictable environments; includes defined physiological phases (prediapause, diapause, postdiapause); 


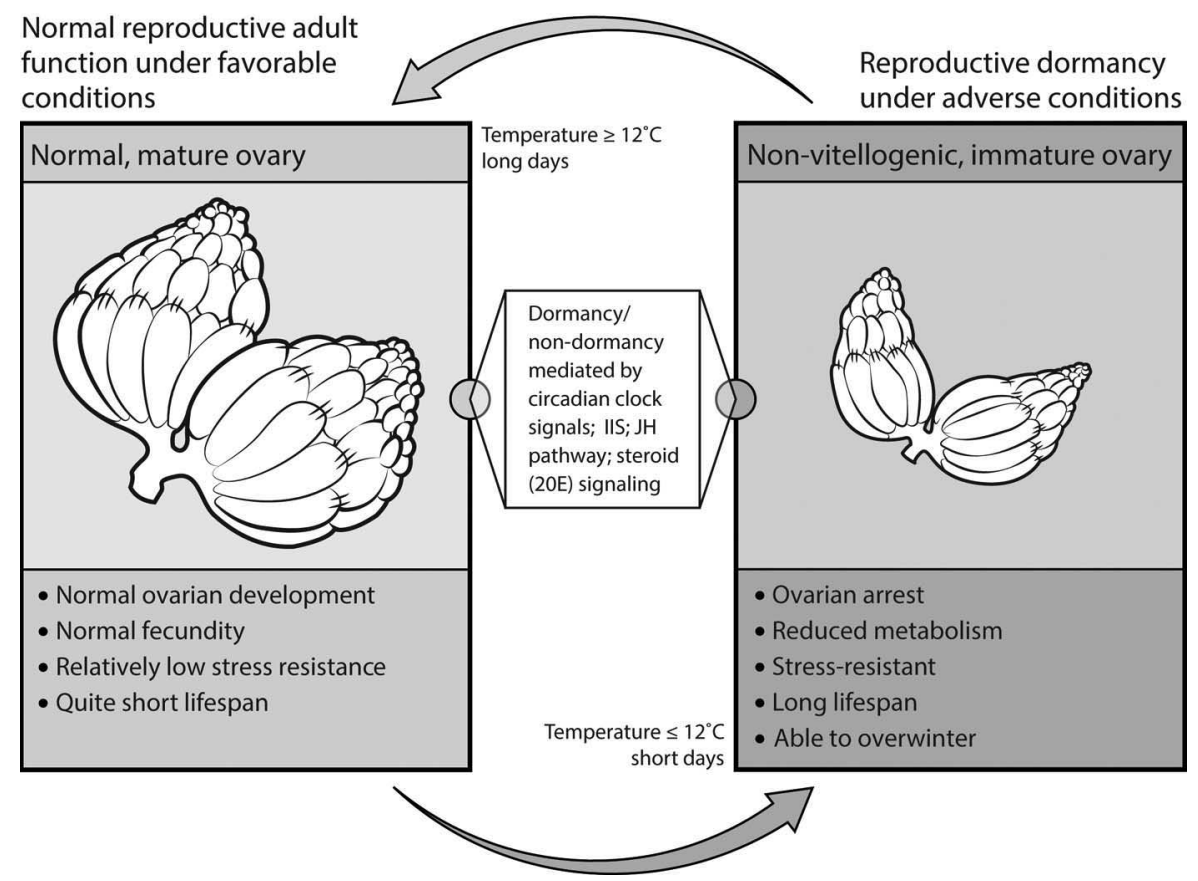

Figure 3. Adult Reproductive Dormancy in Fruit Flies

In response to short day length and cool temperatures, fruit flies (D. melanogaster and related species) can undergo a state of reproductive dormancy, which is associated with ovarian arrest, increased stress resistance, and greatly improved adult survival. Although the details are not yet fully understood, this dormant state appears to be mediated by changes in the circadian clock, the insulin/insulin-like growth factor (IIS), ecdysone (20E), and juvenile hormone (JH) signaling pathways.

is under central neuroendocrine control; and clearly represents an adaptation to (typically seasonally) unfavorable environments (e.g., Danilevskii 1965; Tauber et al. 1986; Danks 1987; Tatar et al. 2001a; Koštál 2006; Schmidt 2011).

In response to low temperatures and short day length, several temperate-zone species of Drosophila enter a state of adult reproductive dormancy, characterized by arrested ovarian development, increased stress resistance, and improved survival ability (e.g., Carson and Stalker 1948; Kambysellis and Heed 1974; Lumme et al. 1974; Lumme 1978; Lumme and Lakovaara 1983; Kimura 1988a,b; Saunders et al. 1989; Tatar and Yin 2001; Tatar et al. 2001a; Tatar 2004; Schmidt et al. 2005a,b; Schmidt and Paaby 2008; Schmidt 2011; Figure 3). Although most authors refer to this phenomenon as reproductive or ovarian "diapause," at least in D. melanogaster this state of reproduc- tive dormancy is quite weak, lacking both a preparatory prediapause and a postdiapause phase, and with dormancy induction being rapid, taking place within a few days after eclosion (e.g., Saunders et al. 1989; Saunders and Bertossa 2011). This dormant state might thus not qualify as a proper diapause but might rather represent quiescence, although there is still some debate about this issue (e.g., Tatar et al. 2001a; Emerson et al. 2009b; Schmidt 2011); for simplicity here we use the neutral term "reproductive dormancy."

The biology of reproductive dormancy is best understood in D. melanogaster (e.g., Saunders et al. 1989, 1990; Saunders and Gilbert 1990; Tatar and Yin 2001; Tatar et al. 2001a; Schmidt 2011). In this species, flies enter dormancy at temperatures $\leq$ $12-13^{\circ} \mathrm{C}$ and short-day photoperiod $(\leq 12$ hours light). In response to these conditions, flies exhibit ovarian arrest (blocked vitello- 
genesis), improved resistance to oxidative and heat stress, and strongly reduced rates of senescence during diapause (e.g., Saunders et al. 1989, 1990; Saunders and Gilbert 1990; Tatar et al. 2001a; Schmidt et al. 2005a,b; Schmidt and Paaby 2008). This state of dormancy is reversible and can be "broken" by higher temperature and longer photoperiod (e.g., Saunders and Gilbert 1990). Yet, whether flies enter dormancy or not, and to what extent dormancy is triggered by temperature and/or photoperiod, depends on their genotype and geographic origin (latitude; e.g., Saunders et al. 1989; Williams and Sokolowski 1993; Mitrovski and Hoffmann 2001; Tatar et al. 2001a; Schmidt et al. 2005a,b; Emerson et al. 2009b; Schmidt 2011). In particular, while certain genotypes can readily enter reproductive dormancy under dormancy-inducing conditions, others cannot. This suggests the existence of substantial amounts of genetic variation and genotype-by-environment $(\mathrm{GxE})$ interactions for dormancy expression (e.g., Schmidt et al. 2005b, 2008). As compared to "low-dormancy" genotypes (i.e., those that are unable to undergo dormancy under dormancy-inducing conditions), "high dormancy" genotypes (i.e., those that always undergo dormancy under dormancyinducing conditions) are characterized by constitutively longer life span (i.e., median female life span is about 50 days as compared to 35 days in nondormancy genotypes), reduced age-specific mortality, lower early fecundity, improved resistance to starvation and cold stress, increased lipid sequestration, and a suite of other phenotypes, even when measured under nondormancy-inducing conditions (Schmidt et al. 2005b). Reproductive dormancy is thus a pleiotropic life-history syndrome, with multiple fitness traits being coordinately expressed in response to specific environmental cues (Flatt et al. 2005; Schmidt 2011). Similar kinds of reproductive dormancy have been described for grasshoppers and butterflies as well as other insects (e.g., Pener 1972; Nijhout 1994; Herman and Tatar 2001; Tatar and Yin 2001; Flatt et al. 2005).

The available evidence indicates that reproductive dormancy in D. melanogaster (and presumably other species) is a life-history adaptation that is most likely associated with the ability of flies to overwinter (e.g., Izquierdo 1991; Mitrovski and Hoffmann 2001; Boulétreau-Merle and Fouillet 2002; Hoffmann et al. 2003). This notion is consistent with the observation from population genetic studies that some genotypes in local fly populations of temperate regions persist over long time periods, implying that the flies overwinter (e.g., Ives $1945,1970)$. Moreover, the ability to undergo dormancy varies predictably with latitude, with flies in temperate northern populations having a much greater propensity to become dormant than flies from southern populations, suggesting that the ability to express dormancy is a seasonal adaptation that has evolved along latitudinal gradients (Schmidt et al. 2005a). Flies from ancestral African populations seem unable to undergo dormancy, consistent with the idea that dormancy is a recent evolutionary adaptation to temperate climates of an ancestrally tropical insect that has become cosmopolitan (Schmidt 2011). Additional evidence for the adaptive nature of reproductive dormancy comes from population cage experiments in the laboratory where, under stressful environmental conditions (i.e., bouts of starvation and cold stress), the frequency of genotypes able to express dormancy increased over time relative to the frequency of nondormant genotypes, whereas under favorable control conditions the reverse was observed (Schmidt and Conde 2006).

Like dauer diapause in nematodes, reproductive dormancy in Drosophila matches the defining criteria of polyphenism (e.g., Nijhout 2003). First, reproductive dormancy is clearly environmentally induced; seems to be adaptive; and involves a switch between two qualitatively discrete suites of life-history traits. Nondormant flies express a life-history "program" that favors reproduction at the expense of somatic maintenance and survival, whereas dormant flies express a "program" that favors somatic maintenance, stress resistance, and survival at the expense of reproduction (e.g., Flatt and Schmidt 2009; Paaby and Schmidt 2009; Schmidt 2011; Figures 1 and 3). Second, reproductive dormancy appears to be an environmentally sensitive threshold trait whose expression is triggered by reliable and predictable environmental token cues, namely 
seasonally predictable changes in temperature and/or photoperiod. Moreover, reproductive dormancy is under strong neuroendocrine control (see below).

\section{WORKER POLYPHENISM IN A. MELLIFERA}

In contrast to C. elegans and D. melanogaster, individuals of the A. mellifera worker caste usually do not reproduce directly. Honey bee reproduction is defined as the production of male individuals (drones) and of daughter colonies that "bud off" from the mother colony by a process of fission called swarming (Winston 1987). To reproduce, a colony must build up to the critical size that enables fission in parallel with the production of drones and new queens (Lee and Winston 1987). Colony size is defined by the number of workers. Workers, queens, and drones are produced during favorable ambient (summer) conditions with the majority of resources allocated to worker rearing, since swarming requires 10,000 workers or more, but only one new queen (Winston 1987). Worker numbers are critical to colony function since the workers (with the exception of egg laying) are responsible for all colony behaviors, such as hygiene, caregiving, construction, foraging, and defense. Workers divide labor based on a system of temporal or "age" polyethism in summer in which individuals perform different tasks in sequence as they age-i.e., a sort of sequential behavioral polyphenism (Seeley 1982; Figure 4). Within-nest activities, such as nest hygiene, caregiving (often called nursing), and construction, are typically performed prior to outside-nest activities like foraging. Summer workers make this transition to outside-nest activities around their third or fourth week of life and only survive another seven to 18 days as foragers (Visscher and Dukas 1997; Dukas 2008). Colony reproduction and foraging activities cease in the fall, and workers enter an alternative phenotypic state with a mean life span of greater than 100 days, with reported maxima between 212 and 304 days (Maurizio 1950; Fukuda and Sekiguchi 1966; Sakagami and Fukuda 1968; Mattila et al. 2001 and references therein); in contrast, "spring" and "summer" bees have a mean life span of approximately only 30-40 days and 25-30 days, respectively (Fukuda and Sekiguchi 1966).

Although seasonal in principle, the longlived worker phenotype of $A$. mellifera is not triggered by ambient cues but rather tied to the dynamic demography of the colony (Maurizio 1950; Amdam and Omholt 2002). The phenotype is called "diutinus" worker (Latin for long-lived) or winter bee, but is also triggered in summer if the brood (eggs, larvae, and pupae) is removed from the colony (Maurizio 1950; Amdam et al. 2004; Figure $4)$. This removal simulates the social environmental conditions of winter, when very little brood is produced, but also conditions that may occur short-term during swarming, while the colony waits for its new queen to mature, mate, and begin egg laying. The winter bee state is "broken" when brood rearing commences as it does naturally in spring, and workers develop summer bee characteristics with division of labor and short life spans (Sakagami and Fukuda 1968; Terada et al. 1975).

Honey bees originated in Africa (Whitfield et al. 2006), and the long-lived worker bee is likely an adaptation to life in temperate zones (Amdam et al. 2005). In accordance with this idea, the ability to produce "diutinus" or winter bees is not equally present among $A$. mellifera subspecies. For example, it is absent from African A. mellifera scutellata as well as from the scutellata hybrids called Africanized bees in America, which have consequently been unable yet to colonize areas north of California (Terada et al. 1975; Amdam et al. 2005). Winter bees are resistant to the oxidative stress-inducing agent paraquat (Seehuus et al. 2006) and to starvation, and they show reduced accumulation of lipofuscin (cellular waste) in the brain as well as intact brain function (i.e., cognitive function as measured by a olfactory learning performance assay) for more than 200 days (D. Muench, G. V. Amdam, unpublished data). In comparison, summer bees are sensitive to paraquat, with foragers being more susceptible than nest bees (Seehuus et al. 2006). Foragers also show rapid lipofuscin accumulation in the brain and glands (D. Muench, G. V. Amdam, unpublished data), and reduced brain func- 


\section{Summer}

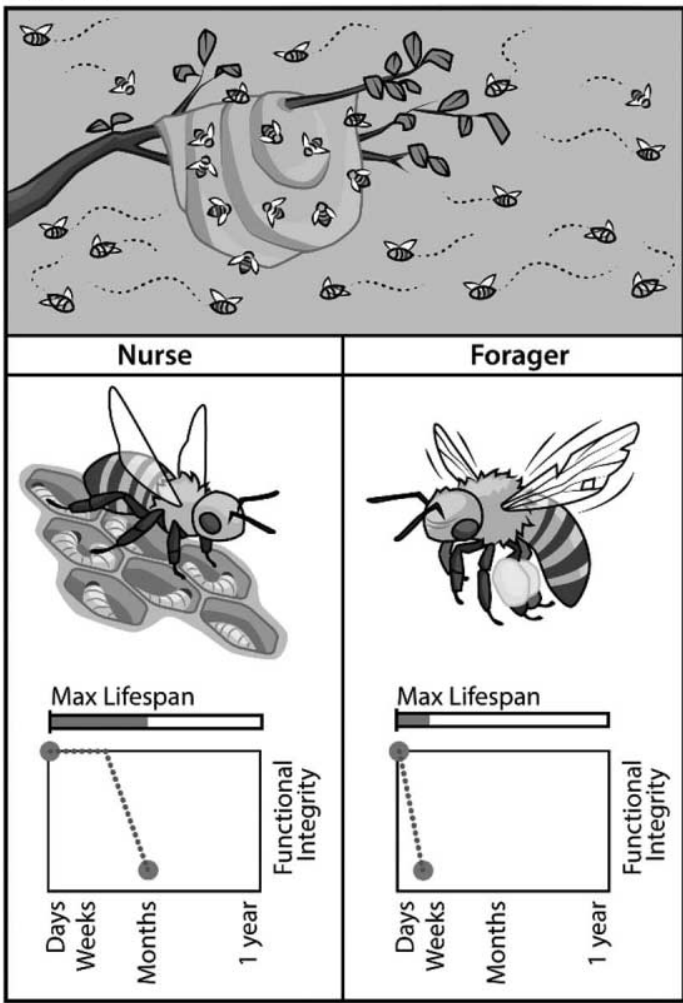

Winter

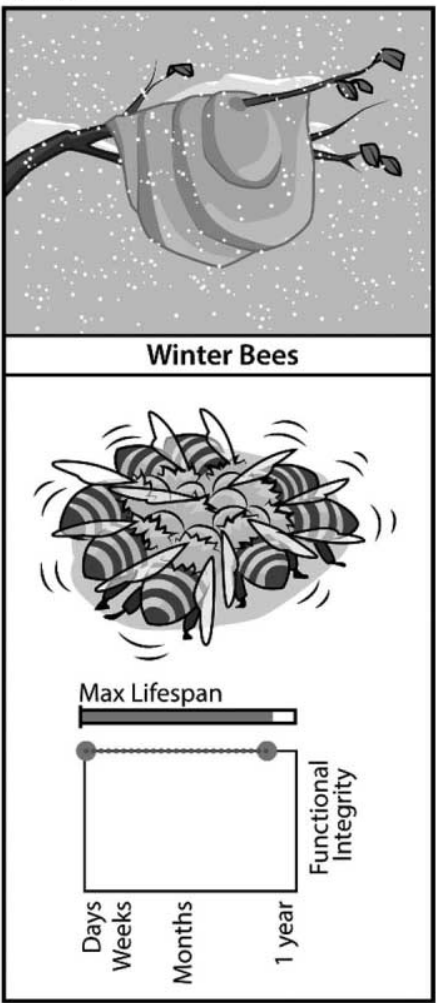

Figure 4. Worker Polyphenism in Honey Bees

In the honey bee (A. mellifera), workers divide labor that is important for colony function (e.g., hygiene, caregiving, construction, foraging, and defense) based on temporal "age polyethism," i.e., a sort of sequential polyphenism. In summer, nurse bees perform within-nest activities (e.g., nest hygiene and cargiving) prior to outside-nest activities such as foraging. In their third or fourth week of life, the nurses transition to become foragers. In fall, colony reproduction and foraging activities cease, and the workers enter a very long-lived phenotypic state called the "diutinus" worker or winter bee. Interestingly, the same state can be elicited in summer if the brood is removed from the colony.

tion after 14 days (Behrends et al. 2007; Scheiner and Amdam 2009).

Like dauer diapause in nematodes and reproductive dormancy in Drosophila, the long-lived worker phenotype of $A$. mellifera fulfills the criteria of polyphenism: it is induced by changes in the (social) environment and seems to involve a switch between two qualitatively discrete sets of life-history traits: summer bees express a suite of life-history traits that favor colony reproduction at the expense of worker somatic maintenance and survival, whereas winter bees express a life-history "program" that favors maintenance, stress resistance, and survival of the colony until the next favorable season (Figures 1 and 4 ). The winter bee state is triggered by a reliable environmental cue, since the absence of brood implies a halt in worker production that requires average worker life spans to increase if colony size and functions are to be maintained (Omholt 1988; Smedal et al. 2009). Similar to worms and flies, this polyphenic switch in bees is also centrally regulated by the endocrine system.

Thus, taken together, the plastic somatic maintenance and survival phenotypes of worms, flies, and bees clearly represent bona fide polyphenisms, and similar prin- 
ciples might apply to other organisms as well ("senescence plasticity"; Tatar and Yin 2001; Figure 1). However, we would also like to point out that the ephemeral polyphenic nature of dauer/reproductive diapause in worms and flies is qualitatively distinct, at least to some extent, from more permanent developmental switches, such as, for example, wing morphs seen in crickets or aphids. Similarly, we note that there is also a certain disjunction between the polyphenic nature of dauer/diapause in worms and flies and that of worker polyphenisms in bees. Nonetheless, all three cases provide clear examples of the plastic regulation of suites of correlated life-history traits, involving profound, environmentally induced changes in somatic maintenance and survival in response to conditions that are unfavorable to reproduction. We now turn to addressing how these adaptive lifehistory switches might have evolved.

\section{Somatic Maintenance and Survival Polyphenisms Evolve By Diversifying Selection}

Mather (1955) laid the foundation for our current understanding of how polyphenic patterns evolve. He suggested that in addition to segregational (genetic) polymorphisms, disruptive (also called diversifying) selection may select for a genotype that is developmentally reactive, by means of a switching mechanism, to some environmental factor such that the "morphic types continue to share a common gene pool" (Mather 1955: 52). Mather thus anticipated that disruptive selection could convert a continuously variable trait into a discontinuous one governed by an environmentally sensitive switch. This was confirmed, for example, by Scharloo (1970) who, by using a negative assortative mating system and artificial disruptive selection targeting cubitus interruptus mutant phenotype expression in Drosophila, was able to obtain a bimodal distribution of the relative length of the fourth wing vein. Genetic analyses of these lines showed that this bimodal distribution is likely caused by a temperature-sensitive threshold mechanism.

The idea that temporally and/or spatially varying environments impose disruptive or diversifying selection that causes the evolution of phenotypic plasticity and polyphenisms ("developmental switches") rather than genetic diversification has been substantially elaborated since (e.g., Levins 1968; Thoday 1972; Mather 1973; Moran 1992; Nijhout 2003; WestEberhard 2003; Berrigan and Scheiner 2004; Leimar et al. 2006; Rueffler et al. 2006). Although plasticity can evolve under both spatial and temporal environmental heterogeneity (e.g., Levins 1968; Berrigan and Scheiner 2004; Leimar 2005; Leimar et al. 2006), theory suggests that it most readily evolves when environments vary temporally, for example, when nonoverlapping generations experience different environments that alternate regularly and that are associated with reliable environmental cues (e.g., Levins 1968; Leimar 2005; Rueffler et al. 2006). This is indeed how seasonal polyphenisms, such as the wet and dry season morphs in tropical butterflies, are thought to have evolved (e.g., Shapiro 1976; Brakefield and Zwaan 2011, and references therein).

The above explanatory scheme is fully consistent with how we believe that the observed somatic maintenance and survival polyphenisms in worms, flies, and bees might have evolved (Figure 1). First, there exists ample genetic variation for the expression of polyphenic life histories in all three systems for selection to act upon, i.e., genotype by environment interactions $(\mathrm{G} \times \mathrm{E})$, and the observed life-history polyphenisms are stably maintained in natural populations (e.g., Viney et al. 2003; Rueppell et al. 2004; Schmidt 2005a,b; Schmidt and Conde 2006; Page and Amdam 2007; Harvey et al. 2008, 2009; Schmidt et al. 2008). Second, diversifying selection, which has likely shaped the evolution of these adaptive switches, appears to be caused in all three species by temporal and/or spatial environmental variation, such that reproductive possibilities are reduced or lacking because of unfavorable conditions in one environment as compared to the other. Third, as we have seen above, in each case the phenotypic switch is associated with reliable environmental cues, a major prerequisite for the evolution of polyphenisms. Finally, in each species, exposure to the unfavorable environment results in stored energy reserves being plastically allocated to somatic maintenance, which allows individu- 
als to survive until conditions have improved. We therefore consider all three polyphenisms to be adaptive. Their existence suggests that variation in the underlying regulatory mechanisms must have been readily available for selection to act upon and thus to shape life-history plasticity. Given that the somatic maintenance and survival polyphenisms of worms, flies, and bees likely share a common selection principle that underlies their evolution, it is interesting to ask what precisely these mechanisms are and to see whether evolution has perhaps led to similar proximate solutions in all three species.

\section{Molecular Basis of Polyphenic Regulation of Somatic Maintenance AND Survival}

The plastic life histories of worms, flies, and bees all require a regulatory machinery that makes switch-like developmental and physiological transitions in response to changes in the environment. These species thus exhibit what we may call polyphenic regulation of somatic maintenance and survival. Over the past few decades, a great deal has been learned about the mechanistic underpinnings of these adaptive life-history switches (see Tatar and Yin 2001; Flatt et al. 2005; Rottiers and Antebi 2006; Braendle et al. 2007; Fielenbach and Antebi 2008; Emerson et al. 2009a; Flatt and Heyland 2011; Gáliková et al. 2011; Gerisch and Antebi 2011; Schiesari et al. 2011; Schmidt 2011; Lee and Schroeder 2012; Schaedel et al. 2012). Based on the currently available evidence, we argue that there are many profound similarities in the proximate regulation of life-history polyphenisms among worms, flies, and bees, particularly at the hormonal level (Figure 5).

\section{MECHANISMS OF DAUER DIAPAUSE IN C. ELEGANS}

The polyphenic regulation of somatic maintenance and survival is mechanistically best understood in C. elegans, a powerful genetic model system. These mechanisms have been reviewed in depth elsewhere; here we give a précis of the molecular regulation of dauer formation as reviewed and discussed by $\mathrm{Hu}$ (2007), Fielenbach and Antebi (2008), and Gerisch and Antebi (2011).
Genetic studies have discovered more than 30 daf genes, mutations which are known to misregulate dauer formation (e.g., Riddle et al. 1981; Albert and Riddle 1988). These loci belong to at least six different functional pathways: sensory neuronal function and perception, including G-proteincoupled receptor (GPCR)/G-protein signaling; neurosensory transduction via cyclic guanosine monophosphate (cGMP) signaling; serotonergic neurotransmission; paracrine and endocrine signaling via the transforming growth factor beta (TGF- $\beta$ ) pathway; insulin/ insulin-like growth factor signaling (IIS); and steroid hormone signaling (see $\mathrm{Hu}$ 2007; Fielenbach and Antebi 2008; Gerisch and Antebi 2011; Lee and Schroeder 2012, and references therein; Figures 2 and 5).

Although the regulatory connections that lead to dauer formation versus reproductive development (i.e., normal development bypassing the dauer) are not strictly hierarchical but should rather be thought of as comprising a highly complex network, including parallel and independent signaling outputs as well as feedback and feedforward loops, a number of major regulatory steps or levels can be recognized (Hu 2007; Fielenbach and Antebi 2008; Gerisch and Antebi 2011).

The first step in the regulation of dauer versus nondauer is the detection, processing, and integration of environmental stimuli and cues, such as nutrition, temperature, and dauer pheromone, by the nervous system; for example, GPCRs that reside in the ciliated endings of neurons situated in the two major head sensory organs, the amphids, detect dauer pheromone and food signals. In turn, these neurosensory signals are transduced via G-proteins and cGMP signaling, including signaling through a transmembrane guanylyl cyclase encoded by daf-11, which converts guanosine triphosphate (GTP) to cGMP, and two subunits of a cGMP-gated ion channel encoded by $\operatorname{tax}-2$ and $\operatorname{tax}-4$, which translate cGMP levels into ion flux. The second step is the integration and transduction of neurosensory signals by the hormonal system: cGMP signaling acts upstream of two major endocrine signaling pathways, TGF- $\beta$ 

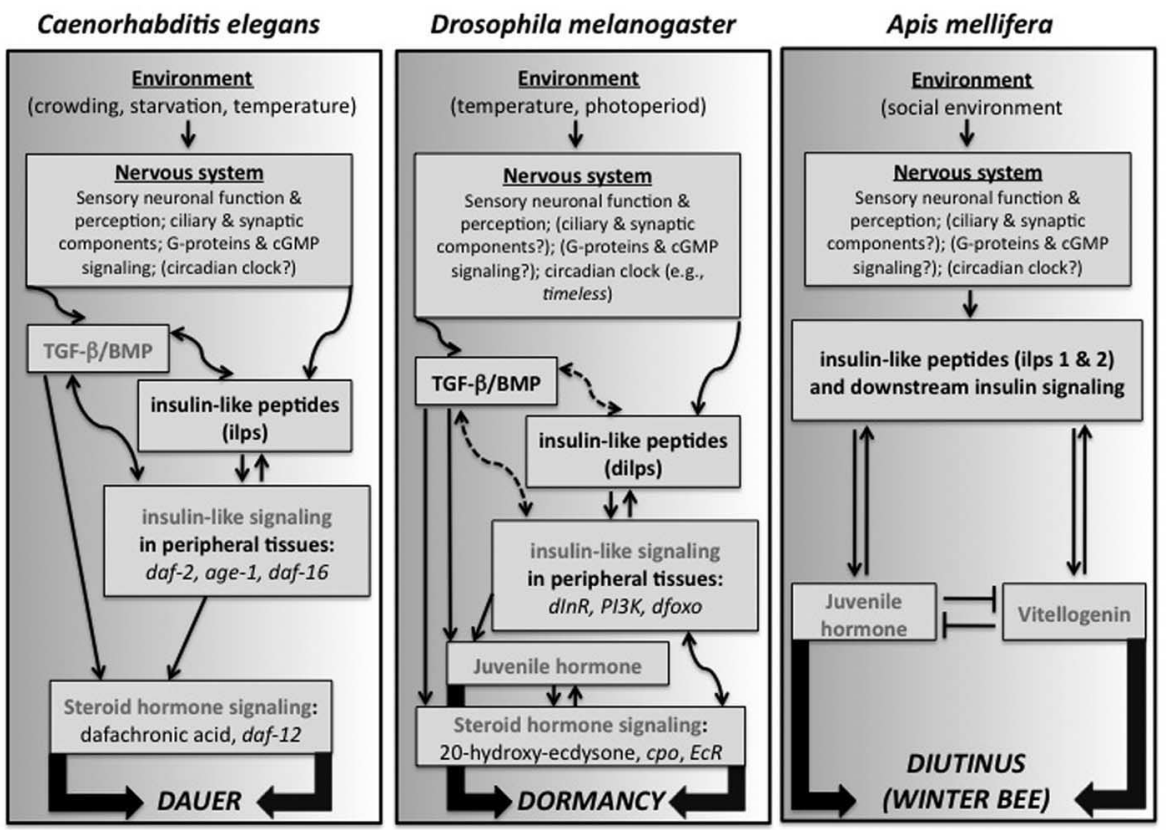

Figure 5. Molecular Pathways Underlying Life-History Polyphenisms in Worms, Flies, and Bees

Comparative models showing the molecular pathways leading to dauer diapause in C. elegans (left panel), reproductive dormancy in $D$. melanogaster (middle panel), and the winter bee (diutinus) state in $A$. mellifera (right panel). Many of the mechanistic details underlying the regulation of these adaptive life-history switches still remain unknown (as indicated by question marks or dashed lines). However, some general regulatory features are beginning to emerge: for example, a central (maybe event dominant) role in all three systems is played by insulin/insulin-like growth factor signaling (IIS). Similarly, in all three cases, IIS seems to regulate the production of lipophilic hormones downstream of IIS, such as the steroid hormones (dafachronic acid or 20-hydroxyecdysone) and/or the sesquiterpenoid juvenile hormone. These hormones in turn mediate the switch between two alternative states: a "program" expressed under normal environmental conditions that promotes reproduction at the expense of somatic maintenance and survival and an alternative "program," expressed under suboptimal or stressful conditions, which promotes somatic maintenance, stress resistance, and survival at the expense of reproduction.

signaling and IIS, and-under conditions of reproductive development-high levels of cGMP stimulate the production of hormone ligands, i.e., TGF- $\beta$ and insulin-like peptides (ilps). In various target tissues, binding of the ilp ligands to the insulin-like receptor encoded by daf-2 sets off the IIS cascade, which involves a series of phosphorylation steps that leads to the cytoplasmic retention and inactivation of the forkhead box-O transcription factor Foxo encoded by $d a f-16$. Similarly, the TGF- $\beta$ ligand encoded by daf-7 activates TGF- $\beta$ signaling in target tissues by binding to two TGF- $\beta$ receptors encoded by daf-1 and daf-4. This in turn leads to the phosphorylation and nuclear localization of two nuclear effectors of the pathway, so-called SMADs (the term is a merger of the names of the Mad-mothers against decapentaplegic - gene in D. melanogaster and the Sma genes in C. elegans), encoded by $d a f-8$ and daf- 14 . Notably, TGF- $\beta$ signaling also regulates the production of ilps, and there exists extensive cross-talk between TGF- $\beta$ signaling and IIS. In the third step, the IIS and TGF- $\beta$ signaling pathways converge on the regulation of steroid hormone signaling; in particular, both pathways regulate the production of steroid hormones called dafachronic acids (DA) produced in the neuroendocrine XXX cells, which are ligands of the nuclear/steroid hormone receptor encoded by daf-12. Finally, DA-liganded DAF-12 exerts transcriptional ef- 
fects that promote reproductive development and inhibit dauer formation. In contrast, when IIS or TGF- $\beta$ signaling are downregulated, the expression of steroid hormone biosynthetic enzymes is inhibited; under such conditions, the unliganded DAF-12 receptor promotes the dauer (nonreproductive) program and inhibits reproductive development (also see Rottiers and Antebi 2006; Fielenbach and Antebi 2008; Gerisch and Antebi 2011; Lee and Schroeder 2012; Schaedel et al. 2012; Wollam et al. 2012).

As already mentioned above, many of the mechanisms involved in specifying dauer versus nondauer (including GPCR, serotonin, TGF- $\beta$ signaling, IIS, and steroid hormone signaling) also play a major role in regulating $C$. elegans adult life history, especially somatic maintenance (e.g., energy storage, stress resistance) and survival (e.g., Kenyon et al. 1993; Larsen 1993; Lithgow et al. 1994; Dorman et al. 1995; Larsen et al. 1995; Gems et al. 1998; Apfeld and Kenyon 1999; Alcedo and Kenyon 2004; Rottiers and Antebi 2006; Shaw et al. 2007; Fielenbach and Antebi 2008; Gerisch and Antebi 2011; Lee and Schroeder 2012). The probably most famous example of a gene involved in dauer regulation with known effects on the adult phenotype is the insulin-like receptor gene, daf-2. Modest impairment of daf- 2 causes increased resistance of adults to a variety of stresses and a doubling of adult life span (e.g., Kenyon et al. 1993). Depending on the specific mutant allele, the strength of its phenotypic effects, as well as the maintenance temperature in the laboratory, daf-2 mutants are highly pleiotropic, also affecting traits such as developmental rate, mobility, fat storage, brood size, and the length of the reproductive period; however, many of these traits can be decoupled from longevity (Gems et al. 1998; Dillin et al. 2002; Fielenbach and Antebi 2008; Gerisch and Antebi 2011).

Interestingly, many of the mechanisms that modulate $C$. elegans life history also regulate Drosophila life history (e.g., Tatar and Yin 2001; Flatt et al. 2005; Fielenbach and Antebi 2008; Gáliková et al. 2011; Gerisch and Antebi 2011), as we will discuss next. In fact, it can be argued that the regulation of the dauer stage and its asso- ciated adult phenotypes in $C$. elegans is functionally homologous to the regulation of adult reproductive dormancy in insects such as Drosophila (cf. Tatar and Yin 2001).

\section{MECHANISMS OF REPRODUCTIVE}

DORMANCY IN D. MELANOGASTER

Compared to C. elegans, much less is known about the molecular regulation of reproductive dormancy in $D$. melanogaster. In contrast to the over 30 daf genes affecting C. elegans dauer formation (e.g., Riddle et al. 1981; Albert and Riddle 1988; Fielenbach and Antebi 2008; Gerisch and Antebi 2011), only three loci have so far been implicated in controlling the propensity of $D$. melanogaster to undergo dormancy (for reviews see Emerson et al. 2009a; Schiesari et al. 2011; Schmidt 2011; see below). Nonetheless, the endocrine regulation of reproductive dormancy in flies and other insects is reasonably well understood, and there seem to exist several intriguing parallels between the hormonal mechanisms involved in dauer diapause in worms and adult reproductive dormancy in insects (e.g., Tatar and Yin 2001; Flatt et al. 2005; Tu et al. 2006; Gáliková et al. 2011; Gerisch and Antebi 2011; Schmidt 2011). The mechanisms known to underlie dormancy in $D$. melanogaster can be grouped-somewhat artificially-into two categories: endocrine and circadian/photoperiodic regulation (Figures 3 and 5).

Similar to its role in C. elegans dauer formation, insulin/insulin-like growth factor signaling (IIS) also seems to mediate reproductive dormancy in fruit flies and other insects (e.g., Tatar and Yin 2001; Flatt et al. 2005; Tu et al. 2006; Emerson et al. 2009a; Gerisch and Antebi 2011; Schiesari et al. 2011; Schmidt 2011, and references therein). By applying deletion mapping to two natural dormancy variants of D. melanogaster, one line with high diapause expression and the other with low expression, Williams et al. (2006) found a strong association between the propensity of flies to undergo dormancy and natural variation at PI3K (synonyms: Pi3K92E, Dp110), the locus encoding phosphoinositide 3-kinase, an enzyme intimately involved in IIS. Further 
complementation and transgenic analyses showed that a reduction in $P I 3 K$ dosage and function increases dormancy expression, suggesting that reduced IIS might induce a state of adult reproductive dormancy (Williams et al. 2006). Interestingly, the Drosophila PI3K locus is the homolog of age-1 in C. elegans, which is known to regulate dauer formation (e.g., Wolkow et al. 2000), thus lending further support to the homology between dauer diapause and insect reproductive dormancy (Tatar and Yin 2001; Gerisch and Antebi 2011).

Other observations also suggest that IIS might be a major endocrine determinant of dormancy in insects. Various D. melanogaster mutants in the IIS pathway, for example, mutants of the insulin receptor InR (the homolog of $C$. elegans daf-2) or the insulin receptor substrate chico, phenocopy (at least partially) suites of phenotypes observed in the dormancy state, including arrest of vitellogenic egg development, increased stress resistance, and extended life span (e.g., Clancy et al. 2001; Tatar and Yin 2001; Tatar et al. 2001b, 2003; Flatt et al. 2005; $\mathrm{Tu}$ et al. 2006). Moreover, in the mosquito Culex pipiens, RNA interference (RNAi) directed against $I n R$ in nondormant mosquitos reared under long day conditions phenocopies aspects of reproductive diapause, whereas RNAi silencing of the forkhead transcription dfoxo (Drosophila foxo, the homolog of C. elegans daf-16) downstream of IIS in mosquitos programmed to undergo reproductive diapause has the opposite effect (Sim and Denlinger 2008). Taken together, these observations strongly indicate that IIS in insects plays a role in regulating dormancy/diapause that is functionally homologous to that in C. elegans, as previously postulated (Tatar and Yin 2001; Gerisch and Antebi 2011; also see below). In addition, it is noteworthy that major components of IIS not only profoundly affect life span in C. elegans and D. melanogaster, but also seem to influence mammalian and in particular also human longevity. For example, variants of FOXO3A and FOXO1, two human orthologs of $\mathrm{dFOXO/DAF-16,} \mathrm{have} \mathrm{been} \mathrm{associated} \mathrm{with}$ longevity in humans (for a recent review see Kenyon 2010).

Adult reproductive dormancy (and other forms of dormancy/diapause) is also modu- lated by two other major insect hormones, the sesquiterpenoid juvenile hormone $(\mathrm{JH})$ and the steroid hormone ecdysone (20-hydroxyecdysone, 20E), two lipophilic molecules whose production is regulated, at least in part, by IIS (e.g., Nijhout 1994; Tatar and Yin 2001; Flatt et al. 2005; Tu et al. 2006). In larval insects, both hormones are produced in the socalled ring gland, a composite gland complex situated behind the brain: the precursors of $20 \mathrm{E}$ (the final conversion into the active hormone $20 \mathrm{E}$ occurs at the target tissues) are produced in a part of the ring gland called the prothoracic gland, whereas $\mathrm{JH}$ and its precursors are produced in the corpora allata glands or, in Dipterans such as D. melanogaster, in their single corpus allatum (e.g., Nijhout 1994; Gäde et al. 1997; Gilbert et al. 2002; Flatt et al. 2005; Jones and Jones 2007). Although the prothoracic gland degenerates at metamorphosis and the gonads become the major ecdysteroidogenic tissue, the corpus allatum persists through metamorphic development and continues to be the adult source of $\mathrm{JH}$. Under dormancy-inducing conditions, the titers of $\mathrm{JH}$ and $20 \mathrm{E}$ are decreased, whereas ectopic treatment of dormant flies with natural or synthetic $\mathrm{JH}$ and 20E terminates their dormancy and restores vitellogenesis (e.g., Saunders et al. 1989, 1990; Richard et al. 1998, 2001a,b; Tatar and Yin 2001; Tatar et al. 2001a; Flatt et al. 2005). In support of the notion that JH plays a major role in regulating dormancy, surgical removal of the corpora allata results in reduced fecundity or sterility and extends life span in grasshoppers, butterflies, bugs, and D. melanogaster, suggesting that $\mathrm{JH}$ is a positive regulator of fecundity, but a negative regulator of life span (e.g., Herman and Tatar 2001; Tatar and Yin 2001; Flatt et al. 2005; Flatt and Kawecki 2007; Hodkova 2008; Tatar et al. 2010; Hodkova and Tatar 2011). However, evidence suggests that the effects of $\mathrm{JH}$ on life span and reproduction may be separable since they can be experimentally uncoupled (Hodkova 2008; Tatar et al. 2010; Hodkova and Tatar 2011). Consistent with the idea that $20 \mathrm{E}$ is an important mediator of dormancy, ecdysteroid titers differ between North American wild-type fly lines that differ in dormancy propensity, with low dormancy lines showing a higher titer under dormancy-inducing conditions than high 
dormancy lines (K. J. Min, T. Flatt, and P. S. Schmidt, unpublished data). Moreover, current evidence suggests that there exist strong genetic and physiological similarities between $20 \mathrm{E} /$ ecdysone receptor $(E c R)$ signaling in Drosophila and dafachronic acid (DA) / daf-12 signaling in C. elegans aging and life history, thus underscoring the importance of steroid hormone signaling in regulating life-history plasticity (Gáliková et al. 2011). Although the mechanistic details await further investigation, it is clear that both $\mathrm{JH}$ and $20 \mathrm{E}$ play important endocrine roles in affecting dormancy propensity.

Several lines of evidence suggest that the production of both $\mathrm{JH}$ and $20 \mathrm{E}$ is regulated by IIS. Hypomorphic mutations at both InR and chico reduce JH biosynthesis levels, and ectopic treatment of sterile long-lived and JH-deficient InR mutant females with synthetic JH (methoprene) partly restores vitellogenesis and reduces life span to wild-type level (Tatar et al. 2001 b; Tu et al. 2005; but also see Richard et al. 2005). Similarly, ovarian ecdysone synthesis is impaired in InR mutant females (Tu et al. 2002), and genetically up- or downregulating IIS in the prothoracic gland increases and decreases circulating ecdysone titers, respectively (Colombani et al. 2005).

The second major candidate gene known to affect dormancy propensity in natural populations of D. melanogaster, couch potato (cpo), also appears to be part of this IIS/ecdysone signaling network. The cpo locus encodes a RNAbinding protein expressed in the peripheral nervous system, in glia cells, the midgut, salivary glands, and-notably-the ring gland (Bellen et al. 1992; Harvie et al. 1998). Using a combination of quantitative trait (QTL) mapping, genetic complementation mapping, and linkage association analysis, Schmidt et al. (2008) found that a single amino acid substitution at $c p o$, which varies clinally along the North American east coast, determines whether flies under dormancy-inducing conditions enter dormancy or not. Interestingly, cpo interacts genetically with $P I 3 K$ in regulating dormancy expression, thus establishing a link between cpo and IIS (Schmidt 2011). Moreover, cpo contains a number of ecdysone response elements, suggesting that cpo might be targeted by or involved in ecdysone signaling (Schmidt et al. 2008). In summary, these observations clearly implicate the neuroendocrine-ovarian IIS/20E signaling axis in the regulation of reproductive dormancy in $D$. melanogaster (e.g., Tatar and Yin 2001; Flatt et al. 2005; Tu et al. 2006; Emerson et al. 2009a; Schiesari et al. 2011; Schmidt 2011). This is consistent with the fact that dormancy expression varies clinally (see above) and with the observation that several major genes in the IIS and $20 \mathrm{E}$ signaling pathways show major genetic differentiation along the Australian and North American latitudinal clines (Kolaczkowski et al. 2011; Fabian et al. 2012).

In addition to the regulation of $20 \mathrm{E}$ and JH by IIS, recent studies have found that $\mathrm{JH}$ and $20 \mathrm{E}$ production are regulated by transforming growth factor $\beta$ (TGF- $\beta$ ) / bone morphogenetic protein (BMP) signaling. The TGF- $\beta$ ligand activin regulates the competence of the prothoracic gland to receive and respond to prothoracicotropic hormone (PTTH) and insulin signals that in turn control the expression of 20E biosynthesis enzymes (Gibbens et al. 2011; also see McBrayer et al. 2007; Rewitz et al. 2009). Similarly, Huang et al. (2011) found that decapentaplegic (DPP)-mediated TGF- $\beta$ /BMP signaling regulates JH biosynthesis by activating the expression of $\mathrm{JH}$ acid methyltransferase (JHAMT). Thus, although it remains unclear whether TGF- $\beta$ /BMP signaling affects reproductive dormancy in Drosophila, these findings suggest that there may be parallels between worms and flies in the TGF$\beta /$ BMP regulation of lipophilic hormones known to be involved in modulating diapause/ dormancy.

The third candidate gene found to affect dormancy in natural populations, timeless $(\mathrm{tim})$, does not seem to be directly involved in the endocrine control of dormancy, but probably plays a role in its photoperiodic regulation (Sandrelli et al. 2007; Tauber et al. 2007; Emerson et al. 2009a; Schiesari et al. 2011; Schmidt 2011). Since dormancy is elicited by a shortening of the photoperiod, its expression is dependent on light and day length. Consequently, the circadian clock, which regulates different kinds of daily rhythms, and the so-called "circa- 
dian" or "clock genes" may be involved in the regulation of dormancy expression, although the link between photoperiodism and circadian rhythms is somewhat controversial (e.g., Saunders 2002; Danks 2005; Emerson et al. 2009a; Saunders and Bertossa 2011; Schiesari et al. 2011; Schmidt 2011). Sandrelli et al. (2007) and Tauber et al. (2007) found that the derived ls-tim mutation at the tim locus has spread by selection over the past 10,000 years in Europe. The ls-tim allele attenuates the photosensitivity of the circadian clock and increases the incidence of ovarian dormancy in response to changes in light and temperature in different genetic backgrounds (Sandrelli et al. 2007; Tauber et al. 2007). Moreover, since dormancy incidence varies clinally, it is interesting to note that some of the clock genes and the cryptochrome (cry) gene, which affects circadian resetting and photosensitivity, are genetically differentiated along the Australian and North American clines (Kolaczkowski et al. 2011; Fabian et al. 2012).

The tim locus then, with its role in photoperiodic regulation of dormancy, represents an example of a mechanism that mediates the sensory perception of an environmental signal. These signals are then integrated and mediated by the endocrine system (e.g., IIS/ ecdysone signaling), and the hormonal signals are in turn translated into the physiological responses underlying dormancy. So what is the connection between circadian rhythms/ photoperiod and the endocrine system? Not much is known, but a few observations suggest that both systems interact quite intimately. In D. melanogaster, neurosecretory cells in the pars intercerebralis (the insulin-producing cells, IPCs) and corpus allatum cells exhibit rhythmic daily changes in nuclear size that might be related to their secretory activity (Rensing 1964), and in several other insects ecdysone and $\mathrm{JH}$ titers undergo circadian/diurnal fluctuations (e.g., Zhao et al. 2004a,b; Steel and Vafopoulou 2006; Polanska et al. 2009; P. Klepsatel, C. Dauphin-Villemant, and T. Flatt, unpublished data). Furthermore, clock genes seem to be strongly expressed in the prothoracic part of the ring gland (Plautz et al. 1997), and Itoh et al. (2011) have recently found that ecdysone signaling is involved in the regulation of circadian oscillations in D. melanogaster.

\section{MECHANISMS OF WORKER POLYPHENISM IN A. MELLIFERA}

The correlation between brood and worker bee life spans led researchers to suspect that brood pheromone, a blend of 10 fatty acid methyl and ethyl esters produced by the larval salivary glands, is the environmental cue that controls the alternative programs of worker longevity (Smedal et al. 2009). Brood pheromone has complex effects on worker gene expression, physiology, and behavior (Pankiw et al. 1998, 2008; Pankiw and Page 2001; Alaux et al. 2009). Importantly, it inhibits adult bees from sequestering a lipoprotein called vitellogenin $(\mathrm{Vg})$ into the abdominal fat body (Smedal et al. 2009), a tissue functionally homologous to mammalian liver and adipose tissue. Vitellogenins are phylogenetically widespread in oviparous animals, where they serve as egg-yolk proteins. Vitellogenin was identified in honey bees about 40 years ago and its reproductive role in queens was instantly recognized (Engels 1974). But, curiously, vitellogenin was also found in considerable amounts in the workers, which are normally sterile. The workers' expression of vitellogenin was first deemed evolutionary baggage, an unavoidable consequence of selection for extreme vitellogenin production rates in queens. Later studies, however, revealed pleiotropic functions: vitellogenin coordinates social behaviors in workers and enhances stress resistance, immunity, and survival in both workers and queens (see Seehuus et al. 2006; Nelson et al. 2007, and references therein). At least some of these functions result from interplay with $\mathrm{JH}$ (Figures 5 and 6 ).

In summer, vitellogenin and $\mathrm{JH}$ act together in a feedback loop to control foraging onset in worker bees (Amdam and Omholt 2003; Figure 6). High vitellogenin levels suppress $\mathrm{JH}$ and foraging behavior, while high $\mathrm{JH}$ levels suppress vitellogenin and nest activities. RNAi experiments confirm that $\mathrm{JH}$ increases when vitellogenin is suppressed (Guidugli et al. 2005), and that vitellogenin knockdown workers forage precociously (Nelson et al. 2007; Marco Antonio et 


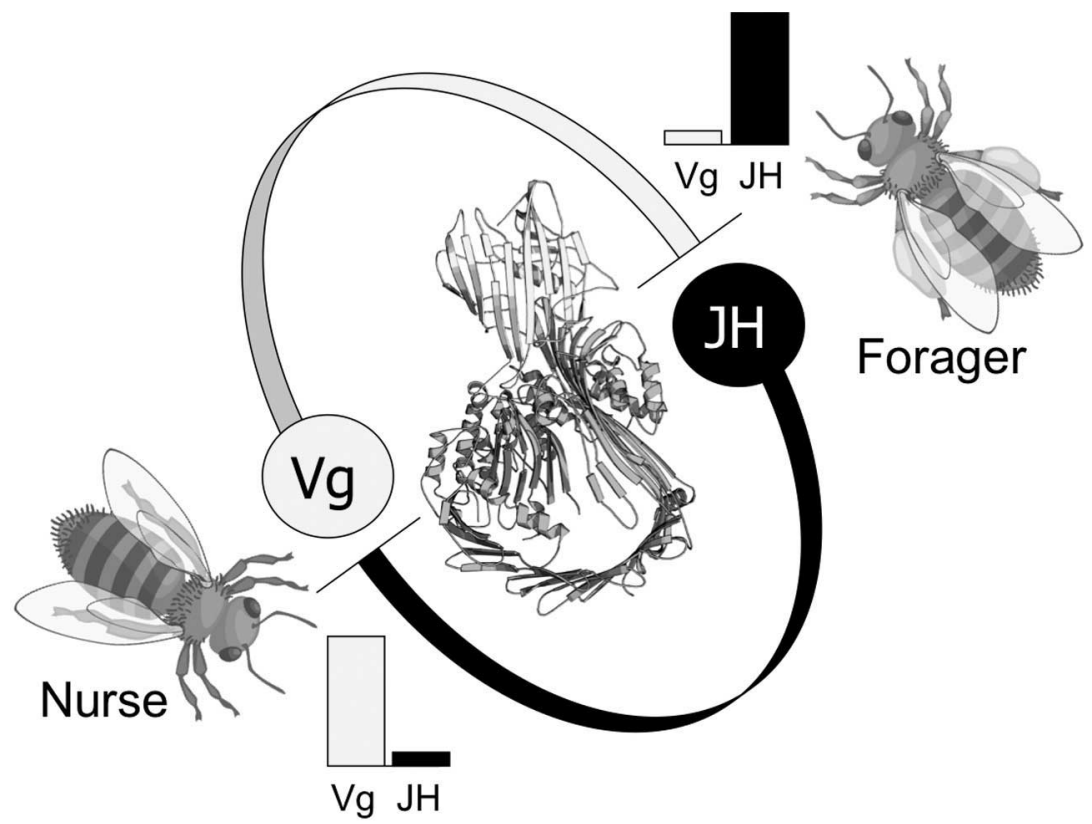

Figure 6. The Vitellogenin (VG)-Juvenile Hormone (JH) Double Repressor Model

Behavioral and life-history maturation in workers of the honey bee (A. mellifera) is regulated by a negative feedback loop between vitellogenin $(\mathrm{Vg})$ and juvenile hormone $(\mathrm{JH})$. In nurse bees, which are characterized by high pollen intake, corpulent bodies, and high levels of stress resistance, Vg titers are high which causes a reduction in JH levels. When workers transition to become foragers, characterized by high nectar intake, lean bodies, and low stress resistance, JH titers increase which causes a drop in Vg levels.

al. 2008). The vitellogenin knockdowns, moreover, are more sensitive to the oxidative stress-inducing agent paraquat and are characterized by reduced longevity independent of when they begin foraging (Seehuus et al. 2006; Nelson et al. 2007). In temperate regions, workers' circulating blood levels of vitellogenin appear to be very high when the brood is absent from colonies (almost $100 \mu \mathrm{g} / \mu \mathrm{l}$ blood) compared to when the brood is present (up to $25 \mu \mathrm{g} / \mu \mathrm{l}$ blood; Amdam et al. 2004, 2005). The very high vitellogenin levels are paralleled by low JH levels (Fluri et al. 1977). The accumulation of vitellogenin in the absence of brood was first explained simply by reduced consumption rates of the protein, as workers expend vitellogenin in the production of proteinaceous food secretions that are fed to brood, queen, and other adult colony members (Amdam and Omholt 2002). However, it was shown later that brood pheromone is sufficient to in- hibit vitellogenin accumulation, suggesting a different level of regulatory control than simple feeding rates, since the actual amount of brood to feed was taken out of the equation (Smedal et al. 2009).

It is currently unknown how honey bee brood pheromones interact with worker physiology to regulate vitellogenin and also how vitellogenin acts, in a molecular sense, to exert its different functions on worker behavior and longevity. Recently, the honey bee vitellogenin gene was found to have been subject to recurrent positive selection in European but not African populations (Kent et al. 2011). We believe this new finding supports the hypothesis that changes in vitellogenin occurred to accommodate colony survival in colder climates during and after the prehistoric migrations of $A$. mellifera from Africa to Europe (Amdam et al. 2005; Seehuus et al. 2006). Kent et al. (2011) discuss 64 single nucleotide polymorphisms (SNPs) that are unequally distributed in the vitel- 
logenin sequence. Roughly dividing the protein into two parts, the N-terminal domain $(\mathrm{N}$ sheet) is resistant to change, while the major lipid-binding cavity is sprinkled with SNP hotspots. The N-sheet contains the phylogenetically conserved, putative receptor-binding domain of vitellogenin that presumably is important for uptake into the ovary (Li et al. 2003). The remaining part of vitellogenin is dominated by a lipid-binding cavity where polymorphisms may alter ligand-binding properties. $\mathrm{JH}$ is a proposed ligand of vitellogenin, as is brood pheromone (Smedal et al. 2009; Nilsen et al. 2011). Alternatively, the general lipid load of vitellogenin might vary in size or composition based on structural features of the cavity and influence traits associated with behavior and survival (Havukainen et al. 2011).

Other studies have connected vitellogenin to IIS. Honey bees have two insulin-like peptides (ilp1 and ilp2), both of which are expressed in the fat body (Nilsen et al. 2011). Expression of $i l p 1$ is correlated with vitellogenin expression, but not affected by vitellogenin knockdown, suggesting that both genes are sensitive to (the same) nutrients. In contrast, ilp2 and vitellogenin are associated indirectly: there is a correlation between ilp2 expression and $\mathrm{JH}$, which is positive when vitellogenin is expressed and negative when vitellogenin is silenced. A model in which ilp1 and ilp2 is the agonist versus antagonist of honey bee insulin receptors, respectively, has been put forward to explain these results, similar to the INS-7 versus INS-1 (insulin-like peptide) agonist/antagonist system of C. elegans (Nilsen et al. 2011). It is, however, unknown whether and how IIS affects honey bee longevity. Correlations between the expression of JH, ilp1, ilp2, and (lifeshortening) foraging activities have been pointed out, but recent data from insulin receptor substrate (IRS) knockdown do not suggest that worker life spans are extended by reduced IIS (K. Ihle, G. V. Amdam, unpublished data). In other words, vitellogenin is the only gene that is functionally validated as a life span regulator in this animal.

\section{The Relevance of Polyphenisms for Molecular Biogerontology}

"Context and interaction are of the essence” (Lewontin 1974:318).
What is the relevance of polyphenisms for somatic maintenance and survival, or more generally of "senescence plasticity" (i.e., phenotypic plasticity in life span or the rate of aging), for molecular biogerontology, which focuses on discovering and understanding genetic effects on life span in model organisms?

The most important point is that lifehistory traits such as life span are characterized by a very high degree of phenotypic plasticity, i.e., the expression of specific life-history phenotypes is highly contingent upon the environment (e.g., Finch 1990; Stearns 1992; Chippindale et al. 1993, 1997; Nylin and Gotthard 1998; Roff 2002; Fielenbach and Antebi 2008; Münch et al. 2008; Flatt and Schmidt 2009; Münch and Amdam 2010; Flatt and Heyland 2011, and references therein). For example, Drosophila life span is highly sensitive to changes in diet (e.g., Mair et al. 2003; Tatar 2007) and temperature (e.g., Maynard Smith 1958; Mair et al. 2003).

An experimentalist who studies, say, the effects of a well-defined gene mutation upon life span, for example, in response to changes in nutrition, temperature, or photoperiod, can view the problem of "senescence plasticity" from two different angles. One angle would be to deliberately ignore the environmental dimension of the problem by treating environmentally engendered variation in life span as a confounding nuisance and thus to strictly control all aspects of the environment so that the experiment is carried out in a single, well-defined, and constant setting. The other angle would be to accept the possibility that a given genotype might exhibit different life spans when exposed to, say, different food levels, and thus to ask whether and how this genotype's life span varies as a function of systematic, controlled changes in food levels. When adopting this point of view, researchers might further anticipate that different genotypes, say the mutant allele versus the "wild-type" allele (the "control"), might differ in their life span response to different environments due to a genotype by environment interaction $(\mathrm{G} \times \mathrm{E}$ interaction; Stearns 1992). These approaches are clearly very different, so what are the impli- 
cations of taking one vantage point versus the other?

One obvious but important implication of the first point of view is that researchers will not be able to generalize the results in terms of making inferences about the phenotypic effects of the mutation on life span in other environments than the one used in the experiment. This is independent of whether a mutation is found to affect life span or not; if the mutation does not alter life span in a specific experiment, researchers cannot be certain that it might not do so in another setting. Therefore, by deliberately ignoring a genotype's "reaction norm" (e.g., Stearns 1992), i.e., the full set of phenotypes (e.g., life spans) produced by a genotype across the full set of environments (e.g., diet levels), researchers cannot address how broadly the experimental results apply or not, thereby restricting "inference space." The alternative approach (i.e., to directly examine the effects of the mutation across different environments) can get around some of these problems, but it faces other difficulties. One is that it is often practically very difficult or even impossible to measure the phenotypic effects of a mutant versus those of a wild-type control at many different levels of the same environmental factor (e.g., more than two diet levels) or to perform the measurements across multiple levels of multiple environmental factors (e.g., simultaneously assessing the effects of diet, temperature, humidity, and photoperiod). Obviously, the experimental design will depend entirely on the specific question, and it would be nonsensical to attempt to examine gene by environment interactions as a function of every conceivable environmental variable. Whatever approach is used, however, experimenters must be very careful when interpreting the data and trying to generalize the findings. For instance, if one measures life span at two temperatures but life span does not change across these temperatures, one can obviously not conclude that the effect of the mutation on life span is generally independent of temperature. The only valid conclusion is that the mutation does not differ in its effect on life span across these two specific temperatures. For two examples of studies that have moved considerably beyond comparing the effects of only two levels of a single environmental factor (e.g., diet: restricted versus ad libitum), see Lee et al. (2008) and Skorupa et al. (2008).

An example from the literature serves to illustrate these points. Hwangbo et al. (2004) discovered that the transcription factor foxo downstream of IIS extends adult life span in Drosophila when overexpressed in the head fat body, a fat layer located above the brain; however, when foxo was overexpressed in the thoracic and abdominal fat tissue, there was no effect on life span. Shortly after this initial discovery, another team reported that, in contrast to the findings by Hwangbo et al. (2004), overexpression in the thoracic and abdominal fat body is also able to extend life span (Giannakou et al. 2004). How can these findings be reconciled? Both laboratories had used slightly different experimental protocols, a fact that led the first team to reevaluate the life span effects of both transgenes (Min et al. 2008). In this study, the authors examined the life span response of overexpressing foxo in both types of fat tissue across four different yeast concentrations in the fly food medium, ranging from $2 \%$ to $12 \%$ yeast. Remarkably, foxo expression in head fat body extended life span only at the two higher yeast levels ( $8 \%$ and $12 \%$ ), whereas activation in thoracic and abdominal fat body only slightly extended life span at $4 \%$, $8 \%$, and $12 \%$, but rather dramatically (by $42 \%)$ at a yeast concentration of $2 \%$. In other words, the two foxo transgenes (i.e., differing in the GAL4 constructs that are used to drive foxo expression) showed very different reaction norms across diet levels. So does foxo overexpression increase adult lifespan? The answer is: it depends. It depends on the interaction between the tissue where the gene is expressed and the concentration of the diet (Min et al. 2008). For further discussion of the issue of $\mathrm{G} \times \mathrm{E}$ interactions in studies of dietary restriction effects on life span see Tatar (2007).

Three general conclusions can be drawn. First, while it is entirely valid to perform ex- 
periments that ignore the potential complexities of phenotypic plasticity and $\mathrm{G} \times \mathrm{E}$ interactions, any conclusions from an experiment are, strictly speaking, valid only for the specific conditions used in that particular experiment. Second, discordant or contradictory findings do not necessarily mean that one research team got it right and the other one got it wrong; instead discrepancies in the results might imply that there is another neglected, unknown, or hidden factor at play (for example, the concentration of yeast in the fly food). Third, when investigating complex quantitative traits known to be highly sensitive to the environment, as is clearly the case with many life-history traits such as life span, one must be acutely aware of the possibility that biologically important dependencies on the environment might exist. In particular, if one studies life-history traits that are inherently plastic, one should not ignore such environmental contingencies. A related, major issue is that standard laboratory conditions often represent very unnatural, unrealistic environments in the first place, which might lead researchers either to miss relevant life-history phenotypes or to misinterpret the relevance of laboratory-based findings for natural environments. For example, standard laboratory conditions can cause a rapid decrease and eventually loss of the ability to undergo reproductive dormancy in $D$. melanogaster since the expression of this polyphenism carries a fitness cost under nonstressful conditions (Schmidt and Conde 2006). Similarly, longterm laboratory culture in C. elegans can result in the loss of the ability to undergo dauer diapause (McGrath et al. 2011). The importance of measuring life-history phenotypes in the "relevant" environment is also underscored by the intriguing observation that fruit flies artificially selected for increased life span in a given laboratory may not show the evolved longevity phenotype when measured in a different laboratory, due to minor differences in assay conditions from laboratory to laboratory (Ackermann et al. 2001). Since life-history traits are often genetically and phenotypically correlated with each other, and since changes in the environment can significantly alter correlations between life-history traits (e.g., Stearns 1992), these considerations not only apply to plasticity of single traits such as life span but also to plasticity of suites of correlated traits. For example, Marden et al. (2003) found that Drosophila mutants of the gene Indy (I am not dead yet) are long-lived without exhibiting any reduction in fecundity on standard food, whereas fecundity was reduced on a lowcalorie diet, suggesting that there exists a conditional tradeoff between life span and reproduction whose expression depends upon diet (also see Flatt 2011).

\section{Life History Polyphenisms and the Evolution of Aging}

The existence of adaptive life-history switches also has specific relevance for examining alternative evolutionary explanations of aging. In particular, polyphenisms are the direct product of an evolved capacity to exhibit phenotypically plastic responses to changes in the environment, but senescence plasticity and the underlying $\mathrm{G} \times \mathrm{E}$ interactions have not to date featured extensively in discussions of the evolution of aging.

Although aging is not an adaptation, the action of natural selection on early fitness components (including survival ability) is thought to be indirectly responsible for the widespread occurrence of senescent decline. The current evolutionary theory of aging identifies three principal ways in which this can occur (e.g., Rose 1991; Partridge and Barton 1993; Kirkwood and Austad 2000; Flatt and Promislow 2007; Flatt and Schmidt 2009; Fabian and Flatt 2011). First, the decline in force of natural selection with age in an iteroparous life history means that any germline mutation affecting fitness only at later ages will be progressively less susceptible to selection, the later the age at which the mutation's effects first become apparent. In the extreme, if such mutations act beyond the normal age range of survival in a natural context where deaths are due chiefly to the hazards of the environment, they can accumulate unchecked even if their effects are deleterious. Should this accumulation 
have occurred, then the transfer of a population to a protected environment would expose individuals to the adverse effects of such mutation accumulation, which might therefore cause phenotypic deterioration and death (Medawar 1952). Second, if the same decline in the force of selection is applied to genes with age-pleiotropic effects, such that the early effects of gene action are beneficial but the later effects of the same genes are deleterious, then selection is predicted to favor the retention of such gene variants (alleles) within the population, even if their late harmful effects cause senescence. This is the concept of antagonistic pleiotropy (Williams 1957). Third, if the physiological costs of somatic maintenance are taken into consideration, the optimal allocation of metabolic resources to such maintenance should be sufficient to prevent significant physical deterioration during the life span typically experienced in the natural environment, but will be insufficient to maintain somatic integrity indefinitely. This is the disposable soma theory (Kirkwood 1977).

All three theories address why species have the life span they do, and they all predict that the principal determinant in the evolution of longevity is the level of extrinsic mortality. If this level is high, life expectancy in the wild is likely to be short, deleterious mutations/alleles accumulate at earlier stages, and there is little selection for a high level of somatic maintenance. Conversely, if the level of extrinsic mortality is low, selection is predicted to postpone deleterious gene effects and to direct greater investment into building and maintaining a durable soma (Kirkwood and Rose 1991; Kirkwood and Austad 2000).

Due to the overlap of their predictions, it has proved somewhat difficult to carry out mutually exclusive tests of the theories. Nevertheless, we can usefully ask whether there are major phenomena related to aging that are: explained by all of them; explained by only one or two of them; or explained by none of them. This may help both to provide a clearer picture of their predictive domains and also to refine our insights into the links between evolutionary theories and the proximate mecha- nisms of aging. Environmentally induced somatic maintenance and survival polyphenisms and their underlying proximal regulatory mechanisms observed in species such as nematodes, fruit flies, and honey bees provide an important test bed in this respect. This is because none of the above theories was explicitly designed to address this type of plastic or polyphenic aging in general, or the aging pattern in the sexually nonreproducing worker caste of honey bees, in particular.

With regard to the mutation accumulation theory, the phenomenon of polyphenic variation in somatic maintenance and survival is not an epiphenomenon that emerges in the "shadow of natural selection," but is a direct product of natural selection derived from the existence of adaptive variation in regulatory mechanisms underlying the environmentally induced variation in somatic maintenance processes. To achieve polyphenic regulation of aging there has to be a signal transduction system that connects environmental conditions with an apparatus to control whether the somatic maintenance machinery should be enhanced or tuned down. Furthermore, this regulatory apparatus will have to include mechanisms to tune up the wide-sense reproductive capability to utilize the resources made available when somatic maintenance is tuned down. The mutation accumulation theory is a purely genetic theory, and since it predicts that the alleles causing aging are effectively beyond the reach of natural selection, it cannot explain the existence of two possible, and very different, somatic maintenance states in one and the same genotype as being a result of natural selection.

In contrast to the mutation accumulation theory, the antagonistic pleiotropy theory proposes that alleles causing aging are not beyond reach of natural selection, but that these alleles are not eliminated from the population because their beneficial effects on fitness at earlier stages more than compensate for their detrimental effects later on. Thus, the antagonistic pleiotropy theory, like the disposable soma theory, is based on the notion of a tradeoff. However, it is still a purely 
genetic theory as its essence is simple selection on individual alleles having agedependent good and bad effects (even though the expression of these genes/alleles can be under environmental influence). Thus, the concept of early- and late-acting alleles does not play an explanatory role in connection with the polyphenic regulation of aging, i.e., the phenomenon that the onset of the different somatic maintenance patterns is dependent on the environmental setting and is not principally a function of the age of the individual. Moreover, concerning the individual phenotype, no regulatory dimension is associated with the current formulation of this theory, and it therefore cannot explain the existence of completely different somatic maintenance regimes in one and the same genotype. The theory does not predict the possibility of bimodal age distributions resulting from alternative somatic maintenance and survival phenotypes in varying environments, which are therefore, at least currently, conceptually beyond its predictive horizon. Nonetheless, it would in principle be possible to develop theoretical models of lifehistory evolution and the evolution of aging based on antagonistically pleiotropic alleles that are subject to $\mathrm{G} \times \mathrm{E}$; to our knowledge, however, this has not been done yet. We would also like to note that there is a somewhat unfortunate tendency in the biogerontological community to often too readily invoke the concept of antagonistic pleiotropy as an explanation for late-life effects of genetic variation in laboratory populations or humans, even though direct genetic evidence for the existence antagonistic pleiotropic alleles and their evolution is lacking in most cases (cf. Flatt and Promislow 2007).

Unlike antagonistic pleiotropy, the disposable soma theory imposes no constraint that individual genes or alleles need to have negatively correlated effects on earlyand late-life fitness since its predictions concern primarily the metabolic allocation of resources among different activities, in particular how these are traded off against somatic maintenance. Although it is sometimes suggested that the disposable soma theory is a mechanistic formulation of the antagonistic pleiotropy theory, this is not in fact the case. Certainly there is some overlap between the predictions of the two theories but, as was made clear by Kirkwood and Rose (1991), selection within the disposable soma theory acts simply to optimize the settings of somatic maintenance functions, and it is not supposed that somatic maintenance has deleterious effects as well as benefits. The genetic architecture underlying the regulation of somatic maintenance is unspecified, so it is open to the existence of pathways that sense the environment and adjust somatic maintenance accordingly, if this is what the optimal life history requires. Indeed, the recent discovery that life span is strongly influenced by evolutionarily conserved signaling pathways that respond to changes in the environment (for example, the IIS/ TOR pathways) is entirely compatible with the predictive framework of the disposable soma theory, as soon as it is recognized that its domain of optimality should extend to include environmental variation (e.g., see Shanley and Kirkwood 2000). The disposable soma theory thus has a prediction set containing important, experimentally substantiated elements that lie beyond the prediction set of antagonistic pleiotropy.

It is worthwhile to consider somewhat more specifically why the disposable soma theory can in principle account for the aging pattern in, for example, a conditionally sterile individual such as the honey bee worker. At the colony level, the honey bee worker can be considered analogous to a somatic cell in sexually reproducing multicellular organisms. Just as the individual (nonmalignant) somatic cell exhibits traits suggestive of "group regulation" at the cell level, so the individual honey bee worker exhibits group regulation at the colony level. Among somatic cells, differences in survival times and responses to stress are likely to have been tuned through selection at the group level, resulting in complex behaviors. For example, mammalian embryonic stem cells appear intrinsically more resistant to stress than their differentiated progeny (e.g., Saretzki et al. 2004). Such behavior was directly predicted in the original presentation of the disposable 
soma theory (Kirkwood 1977), and we believe that the extension to honey bee workers is a natural one, even though they are not genetically identical like somatic cells.

Although the disposable soma theory might have the conceptual potential to include the specific instances of polyphenic regulation of somatic maintenance and survival we have considered here-namely, dauer diapause in C. elegans, reproductive dormancy in D. melanogaster, and worker polyphenism in A. melliferafuture theoretical work will be required to develop mathematically formal, quantitative life-history models, informed by experimental data, which can put this regulation on a firmer footing. This will be valuable in extending our understanding of the links between evolutionary (ultimate) and mechanistic (proximate) factors in the biology of aging and longevity. In a similar vein, and more generally, it will be of great interest to develop extensions of all three evolutionary theories of aging that explicitly accommodate phenotypic plasticity and $\mathrm{G} \times \mathrm{E}$ interactions. This will be an exciting area for future research in life-history theory; for very interesting developments in this direction (albeit not directly dealing with survival and aging), see Leimar (2005, 2009), Leimar et al. (2006), and Schwander and Leimar (2011).

\section{Summary and Conclusions}

Here we have discussed somatic maintenance and survival from the perspective of adaptive polyphenism, i.e., discrete alternative life-history phenotypes that are expressed in response to changes in the environment. We have reviewed empirical evidence suggesting that dauer diapause and its associated phenotypes in the nematode, reproductive dormancy in the fruit fly and other insects, and the worker castes of the honey bee can all be viewed as different manifestations of what we call "polyphenic regulation of somatic maintenance and survival." At the evolutionary level, these adaptive life-history switches all appear to be caused by temporally and/or spatially stressful environments that impose diversifying selection, favoring the evolution of life-history plasticity under strong regulatory control. At the mechanistic level, our review of the available evidence reveals that there exist striking parallels in the regulatory principles that govern the expression of the polyphenisms among the three species, especially with regard to hormonal regulation. We believe that an improved understanding of the links between somatic maintenance and survival polyphenisms and longevity will be a rich ground for pursuing the mechanisms affecting longevity and how these are regulated (e.g., Tatar and Yin 2001). Despite the biological relevance of such somatic maintenance and survival polyphenisms, however, the classical evolutionary theories of aging are silent on the evolution of "senescence plasticity," i.e., they do not predict whether and how plasticity in survival and life span should evolve. Such predictions are currently beyond the explanatory scope of the "mutation accumulation" and "antagonistic pleiotropy" theories, while the framework of the "disposable soma" theory might—at least in principle-be able to account for the evolution of such life-history switches. Thus, from a theoretical perspective, a major future challenge will be to build a predictive evolutionary theory of aging and life histories that explicitly considers plasticity and $\mathrm{G} \times \mathrm{E}$ interactions for survival and life span and that is consistent with classical explanations of why organisms age and die.

\section{ACKNOWLEDGMENTS}

We are grateful to Christian Braendle, Mark Viney, and Ricardo Azevedo for critical comments on the manuscript and to all of the other members of the Adaptive Plasticity Focus Group at the Wissenschaftskolleg zu Berlin for stimulating discussions. We also would like to thank Daniel Dykhuizen and two anonymous reviewers for very helpful comments on a previous version of this paper. We are also indebted to James Baxter and Sabine Deviche for their help with the illustrations. Due to space limitations, we could not always cite primary research papers but had to cite reviews instead; we apologize to our colleagues whose work we could not discuss. Thomas Flatt was supported by the Austrian Science Foundation (FWF \#P21498-B11), the Wissenschaftskolleg zu Berlin, where parts of this paper were written, and the Swiss National Science Foundation (SNF Professorship Grant PP00P3_133641). Gro V. Amdam was supported by grants from the Research Council of Norway (180504, 185306, 191699, 213976/F20), the PEW Charitable Trust, and the National Institute on Aging (PO1AG22500). Part of this work was also supported by, and carried out within, the EU funded Network of Excellence LifeSpan (FP6 036894). 


\section{REFERENCES}

Ackermann M., Pletcher S. D. 2007. Evolutionary biology as a foundation for studying aging and agingrelated disease. Pages 241-252 in Evolution in Health and Disease, edited by S. C. Stearns and J. C. Koella. Oxford (United Kingdom): Oxford University Press.

Ackermann M., Bijlsma R., James A. C., Partridge L., Zwaan B. J., Stearns S. C. 2001. Effects of assay conditions in life history experiments with Drosophila melanogaster. Journal of Evolutionary Biology 14:199-209.

Ailion M., Thomas J. H. 2000. Dauer formation induced by high temperatures in Caenorhabditis elegans. Genetics 156:1047-1067.

Alaux C., Le Conte Y., Adams H. A., Rodriguez-Zas S., Grozinger C. M., Sinha S., Robinson G. E. 2009. Regulation of brain gene expression in honey bees by brood pheromone. Genes, Brain and Behavior 8:309-319.

Albert P. S., Riddle D. L. 1988. Mutants of Caenorhabditis elegans that form dauer-like larvae. Developmental Biology 126:270-293.

Alcedo J., Kenyon C. 2004. Regulation of C. elegans longevity by specific gustatory and olfactory neurons. Neuron 41:45-55.

Amdam G. V. 2011. Social context, stress, and plasticity of aging. Aging Cell 10:18-27.

Amdam G. V., Omholt S. W. 2002. The regulatory anatomy of honeybee lifespan. Journal of Theoretical Biology 216:209-228.

Amdam G. V., Omholt S. W. 2003. The hive bee to forager transition in honeybee colonies: the double repressor hypothesis. Journal of Theoretical Biology 223:451-464.

Amdam G. V., Hartfelder K., Norberg K., Hagen A., Omholt S. W. 2004. Altered physiology in worker honey bees (Hymenoptera: Apidae) infested by the mite Varroa destructor (Acari: Varroidae): a factor in colony loss during overwintering? Journal of Economical Entomology 97:741-747.

Amdam G. V., Norberg K., Omholt S. W., Kryger P., Lourenço A. P., Bitondi M. M. G, Simões Z. L. P. 2005. Higher vitellogenin concentrations in honey bee workers may be an adaptation to life in temperate climates. Insectes Sociaux 52:316-319.

Apfeld J., Kenyon C. 1999. Regulation of lifespan by sensory perception in Caenorhabditis elegans. Nature 402:804-809.

Bateson P., Barker D., Clutton-Brock T., Deb D., D'Udine B., Foley R. A., Gluckman P., Godfrey K., Kirkwood T. B. L., Mirazón Lahr M., McNamara J., Metcalfe N. B., Monaghan P., Spencer H. G., Sul$\tan$ S. E. 2004. Developmental plasticity and human health. Nature 430:419-421.

Baugh L. R., Sternberg P. W. 2006. DAF-16/FOXO regulates transcription of cki-1/Cip/Kip and re- pression of lin-4 during C. elegans L1 arrest. Current Biology 16:780-785.

Behrends A., Scheiner R., Baker N., Amdam G. V. 2007. Cognitive aging is linked to social role in honey bees (Apis mellifera). Experimental Gerontology 42:1146-1153.

Beldade P., Mateus A. R. A., Keller R. A. 2011. Evolution and molecular mechanisms of adaptive developmental plasticity. Molecular Ecology 20:1347-1363.

Bellen H. J., Kooyer S., D’Evelyn D., Pearlman J. 1992. The Drosophila couch potato protein is expressed in nuclei of peripheral neuronal precursors and shows homology to RNA-binding proteins. Genes EO Development 6:2125-2136.

Berrigan D., Scheiner S. M. 2004. Modeling the evolution of phenotypic plasticity. Pages 82-97 in Phenotypic Plasticity: Functional and Conceptual Approaches, edited by T. J. DeWitt and S. M. Scheiner. Oxford (United Kingdom): Oxford University Press.

Boulétreau-Merle J., Fouillet P. 2002. How to overwinter and be a founder: egg-retention phenotypes and mating status in Drosophila melanogaster. Evolutionary Ecology 16:309-332.

Braendle C. 2012. Pheromones: evolving language of chemical communication in nematodes. Current Biology 22:R294-R296.

Braendle C., Davis G. K., Brisson J. A., Stern D. L. 2006. Wing dimorphism in aphids. Heredity 97 : 192-199.

Braendle C., Milloz J., Félix M.-A. 2007. Mechanisms and evolution of environmental responses in Caenorhabditis elegans. Current Topics in Developmental Biology 80:171-207.

Brakefield P. M., Zwaan B. J. 2011. Seasonal polyphenisms and environmentally induced plasticity in the Lepidoptera: the coordinated evolution of many traits on multiple levels. Pages 243-252 in Mechanisms of Life History Evolution: The Genetics and Physiology of Life History Traits and Trade-Offs, edited by T. Flatt and A. Heyland. Oxford (United Kingdom): Oxford University Press.

Burnell A. M., Houthoofd K., O'Hanlon K., Vanfleteren J. R. 2005. Alternate metabolism during the dauer stage of the nematode Caenorhabditis elegans. Experimental Gerontology 40:850-856.

Butcher R. A., Fujita M., Schroeder F. C., Clardy J. 2007. Small-molecule pheromones that control dauer development in Caenorhabditis elegans. $\mathrm{Na}$ ture Chemical Biology 3:420-422.

Butcher R. A., Ragains J. R., Kim E., Clardy J. 2008. A potent dauer pheromone component in Caenorhabditis elegans that acts synergistically with other components. Proceedings of the National Academy of Sciences of the United States of America 105:1428814292. 
Butcher R. A., Ragains J. R., Li W., Ruvkun G., Clardy J., Mak H. Y. 2009. Biosynthesis of the Caenorhabditis elegans dauer pheromone. Proceedings of the National Academy of Sciences of the United States of America 106:1875-1879.

Canfield M., Greene E. 2009. Phenotypic plasticity and the semantics of polymorphism: a historical review and current perspectives. Pages 65-80 in Phenotypic Plasticity in Insects: Mechanisms and Consequences, edited by $\mathrm{D}$. W. Whitman and T. N. Ananthakrishnan. Enfield (New Hampshire): Science Publishers.

Carson H. L., Stalker H. D. 1948. Reproductive diapause in Drosophila robusta. Proceedings of the $\mathrm{Na}$ tional Academy of Sciences of the United States of America 34:124-129.

Cassada R. C., Russell R. L. 1975. The dauer larva, a post-embryonic developmental variant of the nematode Caenorhabditis elegans. Developmental Biology 46:326-342.

Chippindale A. K., Leroi A. M., Kim S. B., Rose M. R. 1993. Phenotypic plasticity and selection in Drosophila life-history evolution. I. Nutrition and the cost of reproduction. Journal of Evolutionary Biology 6:171-193.

Chippindale A. K., Leroi A. M., Saing H., Borash D. J., Rose M. R. 1997. Phenotypic plasticity and selection in Drosophila life history evolution. 2. Diet, mates and the cost of reproduction. Journal of Evolutionary Biology 10:269-293.

Clancy D. J., Gems D., Harshman L. G., Oldham S., Stocker H., Hafen E., Leevers S. J., Partridge L. 2001. Extension of life-span by loss of CHICO, a Drosophila insulin receptor substrate protein. Science 292:104-106.

Colombani J., Bianchini L., Layalle S., Pondeville E., Dauphin-Villemant C., Antoniewski C., Carré C., Noselli S., Léopold P. 2005. Antagonistic actions of ecdysone and insulins determine final size in Drosophila. Science 310:667-670.

Cook C. D. K. 1968. Phenotypic plasticity with particular reference to three amphibious plant species. Pages 97-111 in Modern Methods in Plant Taxonomy, edited by V. Heywood. London (United Kingdom): Academic Press.

Danilevskii A. S. 1965. Photoperiodism and Seasonal Development of Insects. Edinburgh (United Kingdom): Oliver and Boyd.

Danks H. V. 1987. Insect Dormancy: An Ecological Perspective. Ottawa (Canada): Biological Survey of Canada.

Danks H. V. 2005. How similar are daily and seasonal biological clocks? Journal of Insect Physiology 51: 609-619.

Dillin A., Crawford D. K., Kenyon C. 2002. Timing requirements for insulin/IGF-1 signaling in C. elegans. Science 298:830-834.

Dingle H., Winchell R. 1997. Juvenile hormones as a mediator of plasticity in insect life histories. $A r$ chives of Insect Biochemistry and Physiology 35:359373.

Dorman J. B., Albinder B., Shroyer T., Kenyon C. 1995. The age- 1 and daf- 2 genes function in a common pathway to control the lifespan of Caenorhabditis elegans. Genetics 141:1399-1406.

Dukas R. 2008. Mortality rates of honey bees in the wild. Insectes Sociaux 55:252-255.

Emlen D. J., Nijhout H. F. 2000. The development and evolution of exaggerated morphologies in insects. Annual Review of Entomology 45:661-708.

Engels W. 1974. Occurrence and significance of vitellogenins in female castes of social hymenoptera. American Zoologist 14:1229-1237.

Emerson K. J., Bradshaw W. E., Holzapfel C. M. 2009a. Complications of complexity: integrating environmental, genetic and hormonal control of insect diapause. Trends in Genetics 25:217-225.

Emerson K. J., Uyemura A. M., McDaniel K. L., Schmidt P. S., Bradshaw W. E., Holzapfel C. M. 2009b. Environmental control of ovarian dormancy in natural populations of Drosophila melanogaster. Journal of Comparative Physiology A 195:825829.

Fabian D., Flatt T. 2011. The evolution of aging. $\mathrm{Na}$ ture Education Knowledge 3:9.

Fabian D. K., Kapun M., Nolte V., Kofler R., Schmidt P. S., Schlötterer C., Flatt T. 2012. Genome-wide patterns of latitudinal differentiation among populations of Drosophila melanogaster from North America. Molecular Ecology 21:4748-4769.

Félix M.-A., Braendle C. 2010. The natural history of Caenorhabditis elegans. Current Biology 20:R965R969.

Fielenbach N., Antebi A. 2008. C. elegans dauer formation and the molecular basis of plasticity. Genes E Development 22:2149-2165.

Finch C. E. 1990. Longevity, Senescence, and the Genome. Chicago (Illinois): University of Chicago Press.

Finch C. E., Rose M. R. 1995. Hormones and the physiological architecture of life-history evolution. Quarterly Review of Biology 70:1-52.

Flatt T. 2011. Survival costs of reproduction in Drosophila. Experimental Gerontology 46:369-375.

Flatt T., Heyland A. 2011. Mechanisms of Life History Evolution: The Genetics and Physiology of Life History Traits and Trade-Offs. Oxford (United Kingdom): Oxford University Press.

Flatt T., Kawecki T. J. 2007. Juvenile hormone as a regulator of the trade-off between reproduction and life span in Drosophila melanogaster. Evolution 61:1980-1991.

Flatt T., Promislow D. E. L. 2007. Still pondering an age-old question. Science 318:1255-1256.

Flatt T., Schmidt P. S. 2009. Integrating evolutionary 
and molecular genetics of aging. Biochimica et Biophysica Acta 1790:951-962.

Flatt T., Tu M.-P., Tatar M. 2005. Hormonal pleiotropy and the juvenile hormone regulation of Drosophila development and life history. BioEssays 27: 999-1010.

Fluri P., Wille H., Gerig L., Lüscher M. 1977. Juvenile hormone, vitellogenin and haemocyte composition in winter worker honeybees (Apis mellifera). Experientia 33:1240-1241.

Fuchs S., Bundy J. G., Davies S. K., Viney J. M., Swire J. S., Leroi A. M. 2010. A metabolic signature of long life in Caenorhabditis elegans. BMC Biology 8:14.

Fukuda H., Sekiguchi K. 1966. Seasonal change of the honeybee worker longevity in Sapporo, North Japan, with notes on some factors affecting the lifespan. Japanese Journal of Ecology 16:206-212.

Gäde G., Hoffmann K. H., Spring J. H. 1997. Hormonal regulation in insects: facts, gaps, and future directions. Physiological Reviews 77:963-1032.

Gáliková M., Klepsatel P., Senti G., Flatt T. 2011. Steroid hormone regulation of C. elegans and Drosophila aging and life history. Experimental Gerontology 46:141-147.

Gallo M., Riddle D. L. 2009. Effects of a Caenorhabditis elegans dauer pheromone ascaroside on physiology and signal transduction pathways. Journal of Chemical Ecology 35:272-279.

Gems D., Sutton A. J., Sundermeyer M. L., Albert P. S., King K. V., Edgley M. L., Larsen P. L., Riddle D. L. 1998. Two pleiotropic classes of daf-2 mutation affect larval arrest, adult behavior, reproduction and longevity in Caenorhabditis elegans. Genetics 150:129-155.

Gerisch B., Antebi A. 2011. Molecular basis of life history regulation in C. elegans and other organisms. Pages 284-298 in Mechanisms of Life History Evolution: The Genetics and Physiology of Life History Traits and Trade-Offs, edited by T. Flatt and A. Heyland. Oxford (United Kingdom): Oxford University Press.

Giannakou M. E., Goss M., Jünger M. A., Hafen E., Leevers S. J., Partridge L. 2004. Long-lived Drosophila with overexpressed $\mathrm{dFOXO}$ in adult fat body. Science 305:361.

Gibbens Y. Y., Warren J. T., Gilbert L. I., O'Connor M. B. 2011. Neuroendocrine regulation of Drosophila metamorphosis requires TGF $\beta$ /activin signaling. Development 138:2693-2703.

Gilbert L. I., Rybczynski R., Warren J. T. 2002. Control and biochemical nature of the ecdysteroidogenic pathway. Annual Review of Entomology 47:883-916.

Golden J. W., Riddle D. L. 1982. A pheromone influences larval development in the nematode Caenorhabditis elegans. Science 218:578-580.

Golden J. W., Riddle D. L. 1984a. A pheromoneinduced developmental switch in Caenorhabditis el- egans: temperature-sensitive mutants reveal a wildtype temperature-dependent process. Proceedings of the National Academy of Sciences of the United States of America 81:819-823.

Golden J. W., Riddle D. L. 1984b. The Caenorhabditis elegans dauer larva: developmental effects of pheromone, food, and temperature. Developmental Biology 102:368-378.

Golden J. W., Riddle D. L. 1984c. A Caenorhabditis elegans dauer-inducing pheromone and an antagonistic component of the food supply. Journal of Chemical Ecology 10:1265-1280.

Grosberg R. K. 1988. Life-history variation within a population of the colonial ascidian Botryllus schlosseri. I. The genetic and environmental control of seasonal-variation. Evolution 42:900-920.

Guidugli K. R., Nascimento A. M., Amdam G. V., Barchuk A. R., Omholt S. W., Simões Z. L. P., Hartfelder K. 2005. Vitellogenin regulates hormonal dynamics in the worker caste of a eusocial insect. FEBS Letters 579:4961-4965.

Harvey S. C., Shorto A., Viney M. E. 2008. Quantitative genetic analysis of life-history traits of Caenorhabditis elegans in stressful environments. $B M C$ Evolutionary Biology 8:15.

Harvey S. C., La Barker G., Shorto A., Viney M. E. 2009. Natural variation in gene expression in the early development of dauer larvae of Caenorhabditis elegans. BMC Genomics 10:325.

Harvie P. D., Filippova M., Bryant P. J. 1998. Genes expressed in the ring gland, the major endocrine organ of Drosophila melanogaster. Genetics 149:217231.

Havukainen H., Halskau Ø., Amdam G. V. 2011. Social pleiotropy and the molecular evolution of honey bee vitellogenin. Molecular Ecology 20:51115113.

Herman W. S., Tatar M. 2001. Juvenile hormone regulation of longevity in the migratory monarch butterfly. Proceedings of the Royal Society of London B: Biological Sciences 268:2509-2514.

Hodkova M. 2008. Tissue signaling pathways in the regulation of life-span and reproduction in females of the linden bug, Pyrrhocoris apterus. Journal of Insect Physiology 54:508-517.

Hodkova M., Tatar M. 2011. Parallels in understanding the endocrine control of lifespan with the firebug Pyrrhocoris apterus and the fruit fly Drosophila melanogaster. Pages 171-179 in Mechanisms of Life History Evolution: The Genetics and Physiology of Life History Traits and Trade-Offs, edited by T. Flatt and A. Heyland. Oxford (United Kingdom): Oxford University Press.

Hoffmann A. A., Scott M., Partridge L., Hallas R. 2003. Overwintering in Drosophila melanogaster. outdoor field cage experiments on clinal and laboratory selected populations help to elucidate 
traits under selection. Journal of Evolutionary Biology 16:614-623.

Holt S. J., Riddle D. L. 2003. SAGE surveys C. elegans carbohydrate metabolism: evidence for an anaerobic shift in the long-lived dauer larva. Mechanisms of Ageing and Development 124:779-800.

Hu P. J. 2007. Dauer. In WormBook: The Online Review of C. elegans Biology, edited by the C. elegans Research Community. doi/10.1895/wormbook.1.144.1. http:// www.wormbook.org/chapters/www_dauer/ dauer.html. (Accessed 9 May 2013).

Huang J., Tian L., Peng C., Abdou M., Wen D., Wang Y., Li S., Wang J. 2011. DPP-mediated TGF $\beta$ signaling regulates juvenile hormone biosynthesis by activating the expression of juvenile hormone acid methyltransferase. Development 138:2283-2291.

Hunt J. H., Amdam G. V. 2005. Bivoltinism as an antecedent to eusociality in the paper wasp genus Polistes. Science 308:264-267.

Hunt J. H., Kensinger B. J., Kossuth J. A., Henshaw M. T., Norberg K., Wolschin F., Amdam G. V. 2007. A diapause pathway underlies the gyne phenotype in Polistes wasps, revealing an evolutionary route to caste-containing insect societies. Proceedings of the National Academy of Sciences of the United States of America 104:14020-14025.

Hwangbo D. S., Gersham B., Tu M.-P., Palmer M., Tatar M. 2004. Drosophila dFOXO controls lifespan and regulates insulin signalling in brain and fat body. Nature 429:562-566.

Itoh T. Q., Tanimura T., Matsumoto A. 2011. Membranebound transporter controls the circadian transcription of clock genes in Drosophila. Genes to Cells 16:1159-1167.

Ives P. T. 1945. The genetic structure of American populations of Drosophila melanogaster. Genetics 30: 167-196.

Ives P. T. 1970. Further genetic studies on the South Amherst population of Drosophila melanogaster. Evolution 24:507-518.

Izquierdo J. I. 1991. How does Drosophila melanogaster overwinter? Entomologia Experimentalis et Applicata 59:51-58.

Jeong P.-Y., Jung M., Yim Y.-H., Kim H., Park M., Hong E., Lee W., Kim Y. H., Kim K., Paik Y.-K. 2005. Chemical structure and biological activity of the Caenorhabditis elegans dauer-inducing pheromone. Nature 433:541-545.

Johnson T. E., Hartman P. S. 1988. Radiation effects on life-span in Caenorhabditis elegans. Journal of Gerontology 43:B137-B141.

Jones D., Jones G. 2007. Farnesoid secretions of dipteran ring glands: what we do know and what we can know. Insect Biochemistry and Molecular Biology 37:771-798.

Kambysellis M. P., Heed W. B. 1974. Juvenile hormone induces ovarian development in diapausing cave-dwelling Drosophila species. Journal of Insect Physiology 20:1779-1786.

Karp X., Hammell M., Ow M. C., Ambros V. 2011. Effect of life history on microRNA expression during C. elegans development. RNA 17:639-651.

Kawano T., Kataoka N., Abe S., Ohtani M., Honda Y., Honda S., Kimura Y. 2005. Lifespan extending activity of substances secreted by the nematode Caenorhabditis elegans that include the dauer-inducing pheromone. Bioscience, Biotechnology, and Biochemistry 69:2479-2481.

Keller L., Genoud M. 1997. Extraordinary lifespans in ants: a test of evolutionary theories of ageing. $\mathrm{Na}$ ture 389:958-960.

Keller L., Jemielity S. 2006. Social insects as a model to study the molecular basis of ageing. Experimental Gerontology 41:553-556.

Kent C. F., Issa A., Bunting A. C., Zayed A. 2011. Adaptive evolution of a key gene affecting queen and worker traits in the honey bee, Apis mellifera. Molecular Ecology 20:5226-5235.

Kenyon C. 2005. The plasticity of aging: insights from long-lived mutants. Cell 120:449-460.

Kenyon C. 2010. The genetics of ageing. Nature 464: 504-512.

Kenyon C., Chang J., Gensch E., Rudner A., Tabtiang R. 1993. A C. elegans mutant that lives twice as long as wild type. Nature 366:461-464.

Kim K., Sato K., Shibuya M., Zeiger D. M., Butcher R. A., Ragains J. R., Clardy J., Touhara K., Sengupta P. 2009. Two chemoreceptors mediate developmental effects of dauer pheromone in $C$. elegans. Science 326:994-998.

Kimura M. T. 1988a. Adaptations to temperate climates and evolution of overwintering strategies in the Drosophila melanogaster species group. Evolution 42:1288-1297.

Kimura M. T. 1988b. Interspecific and geographic variation of diapause intensity and seasonal adaptation in the Drosophila auraria species complex (Diptera: Drosophilidae). Functional Ecology 2:177183.

Kirkwood T. B. L. 1977. Evolution of ageing. Nature 270:301-304.

Kirkwood T. B. L., Austad S. N. 2000. Why do we age? Nature 408:233-238.

Kirkwood T. B. L., Rose M. R. 1991. Evolution of senescence: late survival sacrificed for reproduction. Philosophical Transactions of the Royal Society of London B: Biological Sciences 332:15-24.

Klass M., Hirsh D. 1976. Non-ageing developmental variant of Caenorhabditis elegans. Nature 260:523525.

Kolaczkowski B., Kern A. D., Holloway A. K., Begun D. J. 2011. Genomic differentiation between temperate and tropical australian populations of Drosophila melanogaster. Genetics 187:245-260. 
Koštál V. 2006. Eco-physiological phases of insect diapause. Journal of Insect Physiology 52:113-127.

Larsen P. L. 1993. Aging and resistance to oxidative damage in Caenorhabditis elegans. Proceedings of the National Academy of Sciences of the United States of America 90:8905-8909.

Larsen P. L., Albert P. S., Riddle D. L. 1995. Genes that regulate both development and longevity in Caenorhabditis elegans. Genetics 139:1567-1583.

Lee S. S., Schroeder F. C. 2012. Steroids as central regulators of organismal development and lifespan. PLoS Biology 10:e1001307.

Lee P. C., Winston M. L. 1987. Effects of reproductive timing and colony size on the survival, offspring colony size and drone production in the honey bee (Apis mellifera). Ecological Entomology 12:187195.

Lee K. P., Simpson S. J., Clissold F. J., Brooks R., Ballard J. O. W., Taylor P. W., Soran N., Raubenheimer D. 2008. Lifespan and reproduction in Drosophila: new insights from nutritional geometry. Proceedings of the National Academy of Sciences of the United States of America 105:2498-2503.

Leimar O. 2005. The evolution of phenotypic polymorphism: randomized strategies versus evolutionary branching. American Naturalist 165:669681.

Leimar O. 2009. Environmental and genetic cues in the evolution of phenotypic polymorphism. Evolutionary Ecology 23:125-135.

Leimar O., Hammerstein P., Van Dooren T. J. M. 2006. A new perspective on developmental plasticity and the principles of adaptive morph determination. American Naturalist 167:367-376.

Levins R. 1968. Evolution in Changing Environments: Some Theoretical Explorations. Princeton (New Jersey): Princeton University Press.

Lewontin R. C. 1974. The Genetic Basis of Evolutionary Change. New York: Columbia University Press.

Li A., Sadasivam M., Ding J. L. 2003. Receptor-ligand interaction between vitellogenin receptor (VtgR) and vitellogenin $(\mathrm{Vtg})$, implications on low density lipoprotein receptor and apolipoprotein $\mathrm{B} / \mathrm{E}$ : the first three ligand-binding repeats of $\mathrm{VtgR}$ interact with the amino-terminal region of Vtg. Journal of Biological Chemistry 278:2799-2806.

Lithgow G. J., White T. M., Hinerfeld D. A., Johnson T. E. 1994. Thermotolerance of a long-lived mutant of Caenorhabditis elegans. Journal of Gerontology 49:B270-B276.

Lithgow G. J., White T. M., Melov S., Johnson T. E. 1995. Thermotolerance and extended life-span conferred by single-gene mutations and induced by thermal stress. Proceedings of the National Academy of Sciences of the United States of America 92:75407544.

Ludewig A. H., Schroeder F. C. 2013. Ascaroside signaling in C. elegans. In WormBook: The Online Review of C. elegans Biology, edited by the C. elegans Research Community. doi/10.1895/wormbook.1.155.1. http:// www.wormbook.org/chapters/www_ascarosidesignal/ ascarosidesignal.html. (Accessed 9 May 2013).

Lumme J. 1978. Phenology and photoperiodic diapause in northern populations of Drosophila. Pages 145-169 in Evolution of Insect Migration and Diapause, edited by H. Dingle. New York: Springer.

Lumme J., Lakovaara S. 1983. Seasonality and diapause in Drosophilids. Pages 171-220 in Genetics and Biology of Drosophila, Volume 3, edited by M. Ashburner, H. L. Carson, and J. N. J. Thompson. London (United Kingdom): Academic Press.

Lumme J., Oikarinen A., Lakovaara S., Alatalo R. 1974. The environmental regulation of adult diapause in Drosophila littoralis. Journal of Insect Physiology 20:2023-2033.

Mair W., Goymer P., Pletcher S. D., Partridge L. 2003. Demography of dietary restriction and death in Drosophila. Science 301:1731-1733.

Marco Antonio D. S., Guidugli-Lazzarini K. R., Nascimento A. M., Simões Z. L. P., Hartfelder K. 2008. RNAi-mediated silencing of vitellogenin gene function turns honeybee (Apis mellifera) workers into extremely precocious foragers. Naturwissenschaften 95:953-961.

Marden J. H., Rogina B., Montooth K. L., Helfand S. L. 2003. Conditional tradeoffs between aging and organismal performance of Indy long-lived mutant flies. Proceedings of the National Academy of Sciences of the United States of America 100:33693373.

Mather K. 1955. Polymorphism as an outcome of disruptive selection. Evolution 9:52-61.

Mather K. 1973. Genetical Structure of Populations. London (United Kingdom): Chapman and Hall.

Mattila H. R., Harris J. L., Otis G. W. 2001. Timing of production of winter bees in honey bee (Apis mellifera) colonies. Insectes Sociaux 48:88-93.

Maurizio A. 1950. The influence of pollen feeding and brood rearing on the length of life and physiological condition of the honeybee preliminary report. Bee World 31:9-12.

Maynard Smith J. 1958. The effects of temperature and of egg-laying on the longevity of Drosophila subobscura. Journal of Experimental Biology 35:832842.

Mayr E. 1963. Animal Species and Evolution. Cambridge (Massachusetts): Belknap Press of Harvard University Press.

McBrayer Z., Ono H., Shimell M., Paryy J.-P., Beckstead R. B., Warren J. T., Thummel C. S., Dauphin-Villemant C., Gilbert L. I., O'Connor M. B. 2007. Prothoracicotropic hormone regulates developmental timing and body size in Drosophila. Developmental Cell 13:857-871.

McGrath P. T., Xu Y., Ailion M., Garrison J. L., 
Butcher R. A., Bargmann C. I. 2011. Parallel evolution of domesticated Caenorhabditis species targets pheromone receptor genes. Nature 477:321325.

Medawar P. B. 1952. An Unsolved Problem of Biology. London (United Kingdom): H. K. Lewis.

Min K.-J., Yamamoto R., Buch S., Pankratz M., Tatar M. 2008. Drosophila lifespan control by dietary restriction independent of insulin-like signaling. $A g$ ing Cell 7:199-206.

Mitrovski P., Hoffmann A. A. 2001. Postponed reproduction as an adaptation to winter conditions in Drosophila melanogaster. evidence for clinal variation under semi-natural conditions. Proceedings of the Royal Society of London B: Biological Sciences 268: 2163-2168.

Moran N. A. 1992. The evolutionary maintenance of alternative phenotypes. American Naturalist 139: 971-989.

Münch D., Amdam G. V. 2010. The curious case of aging plasticity in honey bees. FEBS Letters 584: 2496-2503.

Münch D., Amdam G. V., Wolschin F. 2008. Ageing in a eusocial insect: molecular and physiological characteristics of life span plasticity in the honey bee. Functional Ecology 22:407-421.

Nelson C. M., Ihle K. E., Fondrk M. K., Page R. E. Jr., Amdam G. V. 2007. The gene vitellogenin has multiple coordinating effects on social organization. PLoS Biology 5:e62.

Nijhout H. F. 1994. Insect Hormones. Princeton (New Jersey): Princeton University Press.

Nijhout H. F. 2003. Development and evolution of adaptive polyphenisms. Evolution $\mathcal{E} \mathcal{O}$ Development 5:9-18.

Nijhout H. F., Wheeler D. E. 1982. Juvenile hormone and the physiological basis of insect polymorphisms. Quarterly Review of Biology 57:109-133.

Nilsen K.-A., Ihle K. E., Frederick K., Fondrk M. K., Smedal B., Hartfelder K., Amdam G. V. 2011. Insulin-like peptide genes in honey bee fat body respond differently to manipulation of social behavioral physiology. Journal of Experimental Biology 214:1488-1497.

Nylin S., Gotthard K. 1998. Plasticity in life-history traits. Annual Review of Entomology 43:63-83.

Omholt S. W. 1988. Relationships between worker longevity and the intracolonial population dynamics of the honeybee. Journal of Theoretical Biology 130:275-284.

Paaby A. B., Schmidt P. S. 2009. Dissecting the genetics of longevity in Drosophila melanogaster. Fly 3:2938.

Padilla P. A., Ladage M. L. 2012. Suspended animation, diapause and quiescence: arresting the cell cycle in C. elegans. Cell Cycle 11:1672-1679.

Page R. E. Jr., Amdam G. V. 2007. The making of a social insect: developmental architectures of social design. BioEssays 29:334-343.

Pankiw T., Page R. E. Jr. 2001. Brood pheromone modulates honeybee (Apis mellifera L.) sucrose response thresholds. Behavioral Ecology and Sociobiology 49:206-213.

Pankiw T., Page R. E. Jr., Fondrk M. K. 1998. Brood pheromone stimulates pollen foraging in honey bees (Apis mellifera). Behavioral Ecology and Sociobiology 44:193-198.

Pankiw T., Sagili R. R., Metz B. N. 2008. Brood pheromone effects on colony protein supplement consumption and growth in the honey bee (Hymenoptera: Apidae) in a subtropical winter climate. Journal of Economical Entomology 101:1749-1755.

Partridge L., Barton N. H. 1993. Optimality, mutation and the evolution of ageing. Nature 362:305-311.

Partridge L., Gems D., Withers D. J. 2005. Sex and death: what is the connection? Cell 120:461-472.

Pener M. P. 1972. The corpus allatum in adult acridids: the inter-relation of its functions and possible correlations with the life cycle. Pages 135-147 in Proceedings of the International Study Conference on the Current and Future Problems of Acridology, edited by C. F. Hemming and T. H. C. Taylor. London (United Kingdom): Centre for Overseas Pest Research.

Plautz J. D., Kaneko M., Hall J. C., Kay S. A. 1997. Independent photoreceptive circadian clocks throughout Drosophila. Science 278:1632-1635.

Polanska M. A., Maksimiuk-Ramirez E., Ciuk M. A., Kotwica J., Bebas P. 2009. Clock-controlled rhythm of ecdysteroid levels in the haemolymph and testes, and its relation to sperm release in the Egyptian cotton leafworm, Spodoptera littoralis. Journal of Insect Physiology 55:426-434.

Rensing L. 1964. Daily rhythmicity of corpus allatum and neurosecretory cells in Drosophila melanogaster (Meig). Science 144:1586-1587.

Rewitz K. F., Yamanaka N., Gilbert L. I., O'Connor M. B. 2009. The insect neuropeptide PTTH activates receptor tyrosine kinase torso to initiate metamorphosis. Science 326:1403-1405.

Richard D. S., Watkins N. L., Serafin R. B., Gilbert L. I. 1998. Ecdysteroids regulate yolk protein uptake by Drosophila melanogaster oocytes. Journal of Insect Physiology 44:637-644.

Richard D. S., Gilbert M., Crum B., Hollinshead D. M., Schelbe S., Scheswohl D. 2001a. Yolk protein endocytosis by oocytes in Drosophila melanogaster. immunofluorescent localization of clathrin, adaptin and the yolk protein receptor. Journal of Insect Physiology 47:715-723.

Richard D. S., Jones J. M., Barbarito M. R., Cerula S., Detweiler J. P., Fisher S. J., Brannigan D. M., Scheswohl D. M. 2001b. Vitellogenesis in diapausing and mutant Drosophila melanogaster: further ev- 
idence for the relative roles of ecdysteroids and juvenile hormones. Journal of Insect Physiology 47: 905-913.

Richard D. S., Rybczynski R., Wilson T. G., Wang Y., Wayne M. L., Zhou Y., Partridge L., Harshman L. G. 2005. Insulin signaling is necessary for vitellogenesis in Drosophila melanogaster independent of the roles of juvenile hormone and ecdysteroids: female sterility of the chicol insulin signaling mutation is autonomous to the ovary. Journal of Insect Physiology 51:455-464.

Riddle D. L., Albert P. S. 1997. Genetic and environmental regulation of dauer larva development. Pages $739-768$ in C. elegans II, edited by D. L. Riddle, T. Blumenthal, B. J. Meyer, and J. R. Priess. Cold Spring Harbor (New York): Cold Spring Harbor Laboratory Press.

Riddle D. L., Swanson M. M., Albert P. S. 1981. Interacting genes in nematode dauer larva formation. Nature 290:668-671.

Roff D. A. 2002. Life History Evolution. Sunderland (Massachusetts): Sinauer Associates.

Rose M. R. 1991. Evolutionary Biology of Aging. New York: Oxford University Press.

Rottiers V., Antebi A. 2006. Control of Caenorhabditis elegans life history by nuclear receptor signal transduction. Experimental Gerontology 41:904-909.

Ruaud A.-F., Bessereau J.-L. 2006. Activation of nicotinic receptors uncouples a developmental timer from the molting timer in C. elegans. Development 133:2211-2222.

Rueffler C., Van Dooren T. J. M., Leimar O., Abrams P. A. 2006. Disruptive selection and then what? Trends in Ecology and Evolution 21:238-245.

Rueppell O., Pankiw T., Nielson D. I., Fondrk M. K., Beye M., Page R. E. Jr. 2004. The genetic architecture of the behavioral ontogeny of foraging in honey bee workers. Genetics 167:1767-1779.

Sakagami S. F., Fukuda H. 1968. Life tables for worker honeybees. Researches on Population Ecology 10:127139.

Sandrelli F., Tauber E., Pegoraro M., Mazzotta G., Cisotto P., Landskron J., Stanewsky R., Piccin A., Rosato E., Zordan M., Costa R., Kyriacou C. P. 2007. A molecular basis for natural selection at the timeless locus in Drosophila melanogaster. Science 316:1898-1900.

Saretzki G., Armstrong L., Leake A., Lako M., von Zglinicki T. 2004. Stress defense in murine embryonic stem cells is superior to that of various differentiated murine cells. Stem Cells 22:962-971.

Saunders D. S. 2002. Insect Clocks. Amsterdam (The Netherlands): Elsevier.

Saunders D. S., Bertossa R. C. 2011. Deciphering time measurement: the role of circadian "clock" genes and formal experimentation in insect photoperiodism. Journal of Insect Physiology 57:557-566.
Saunders D. S., Gilbert L. I. 1990. Regulation of ovarian diapause in Drosophila melanogaster by photoperiod at moderately low temperature. Journal of Insect Physiology 36:195-200.

Saunders D. S., Henrich V. C., Gilbert L. I. 1989. Induction of diapause in Drosophila melanogaster: photoperiodic regulation and the impact of arrhythmic clock mutations on time measurement. Proceedings of the National Academy of Sciences of the United States of America 86:3748-3752.

Saunders D. S., Richard D. S., Applebaum S. W., Ma M., Gilbert L. I. 1990. Photoperiodic diapause in Drosophila melanogaster involves a block to the juvenile hormone regulation of ovarian maturation. General and Comparative Endocrinology 79:174-184.

Schaedel O. N., Gerisch B., Antebi A., Sternberg P. W. 2012. Hormonal signal amplification mediates environmental conditions during development and controls an irreversible commitment to adulthood. PLoS Biology 10:e1001306.

Scharloo W. 1970. Stabilizing and disruptive selection on a mutant character in Drosophila. III. Polymorphism caused by a developmental switch mechanism. Genetics 65:693-705.

Scheiner R., Amdam G. V. 2009. Impaired tactile learning is related to social role in honeybees. Journal of Experimental Biology 212:994-1002.

Schiesari L., Kyriacou C. P., Costa R. 2011. The hormonal and circadian basis for insect photoperiodic timing. FEBS Letters 585:1450-1460.

Schmidt P. S. 2011. Evolution and mechanisms of insect reproductive diapause: a plastic and pleiotropic life history syndrome. Pages 230-242 in Mechanisms of Life History Evolution: The Genetics and Physiology of Life History Traits and Trade-Offs, edited by T. Flatt and A. Heyland. Oxford (United Kingdom): Oxford University Press.

Schmidt P. S., Conde D. R. 2006. Environmental heterogeneity and the maintenance of genetic variation for reproductive diapause in Drosophila melanogaster. Evolution 60:1602-1611.

Schmidt P. S., Paaby A. B. 2008. Reproductive diapause and life-history clines in North American populations of Drosophila melanogaster. Evolution 62:1204-1215.

Schmidt P. S., Matzkin L., Ippolito M., Eanes W. F. 2005a. Geographic variation in diapause incidence, life-history traits, and climatic adaptation in Drosophila melanogaster. Evolution 59:1721-1732.

Schmidt P. S., Paaby A. B., Heschel M. S. 2005b. Genetic variance for diapause expression and associated life histories in Drosophila melanogaster. Evolution 59:2616-2625.

Schmidt P. S., Zhu C.-T., Das J., Batavia M., Yang L., Eanes W. F. 2008. An amino acid polymorphism in the couch potato gene forms the basis for climatic adaptation in Drosophila melanogaster. Proceedings of 
the National Academy of Sciences of the United States of America 105:16207-16211.

Schwander T., Leimar O. 2011. Genes as leaders and followers in evolution. Trends in Ecology and Evolution 26:143-151.

Seehuus S.-C., Norberg K., Gimsa U., Krekling T., Amdam G. V. 2006. Reproductive protein protects functionally sterile honey bee workers from oxidative stress. Proceedings of the National Academy of Sciences of the United States of America 103:962-967.

Seeley T. D. 1982. Adaptive significance of the age polyethism schedule in honeybee colonies. Behavioral Ecology and Sociobiology 11:287-293.

Shanley D. P., Kirkwood T. B. L. 2000. Calorie restriction and aging: a life-history analysis. Evolution 54:740-750.

Shapiro A. M. 1976. Seasonal polyphenism. Evolutionary Biology 9:259-333.

Shapiro A. M. 1984. Polyphenism, phyletic evolution, and the structure of the pierid genome. Journal of Research on the Lepidoptera 23:177-195.

Shaw W. M., Luo S., Landis J., Ashraf J., Murphy C. T. 2007. The $C$. elegans TGF- $\beta$ dauer pathway regulates longevity via insulin signaling. Current Biology 17:1635-1645.

Sim C., Denlinger D. L. 2008. Insulin signaling and FOXO regulate the overwintering diapause of the mosquito Culex pipiens. Proceedings of the National Academy of Sciences of the United States of America 105:6777-6781.

Simpson S. J., Sword G. A., Lo N. 2011. Polyphenism in insects. Current Biology 21:R738-R749.

Skorupa D. A., Dervisefendic A., Zwiener J., Pletcher S. D. 2008. Dietary composition specifies consumption, obesity, and lifespan in Drosophila melanogaster. Aging Cell 7:478-490.

Smedal B., Brynem M., Kreibich C. D., Amdam G. V. 2009. Brood pheromone suppresses physiology of extreme longevity in honeybees (Apis mellifera). Journal of Experimental Biology 212:3795-3801.

Srinivasan J., Kaplan F., Ajredini R., Zachariah C., Alborn H. T., Teal P. E. A., Malik R. U., Edison A. S., Sternberg P. W., Schroeder F. C. 2008. A blend of small molecules regulates both mating and development in Caenorhabditis elegans. Nature 454:1115-1118.

Stearns S. C. 1976. Life-history tactics: a review of the ideas. Quarterly Review of Biology 51:3-47.

Stearns S. C. 1982. The role of development in the evolution of life histories. Pages 237-258 in Evolution and Development, Dahlem Konferenzen 1982, edited by J. T. Bonner. Berlin (Germany): Springer.

Stearns S. C. 1989. The evolutionary significance of phenotypic plasticity. BioScience 39:436-445.

Stearns S. C. 1992. The Evolution of Life Histories. Oxford (United Kingdom): Oxford University Press.

Steel C. G. H., Vafopoulou X. 2006. Circadian orches- tration of developmental hormones in the insect, Rhodnius prolixus. Comparative Biochemistry and Physiology A 144:351-364.

Taborsky M., Brockmann H. J. 2010. Alternative reproductive tactics and life history phenotypes. Pages 537-586 in Animal Behaviour: Evolution and Mechanisms, edited by P. Kappeler. Berlin (Germany): Springer.

Tatar M. 2004. The neuroendocrine regulation of Drosophila aging. Experimental Gerontology 39:1745-1750.

Tatar M. 2007. Diet restriction in Drosophila melanogaster: design and analysis. Interdisciplinary Topics in Gerontology 35:115-136.

Tatar M., Yin C.-M. 2001. Slow aging during insect reproductive diapause: why butterflies, grasshoppers and flies are like worms. Experimental Gerontology 36:723-738.

Tatar M., Chien S. A., Priest N. K. 2001a. Negligible senescence during reproductive dormancy in Drosophila melanogaster. American Naturalist 158:248-258.

Tatar M., Kopelman A., Epstein D., Tu M.-P., Yin C.-M., Garofalo R. S. 2001b. A mutant Drosophila insulin receptor homolog that extends life-span and impairs neuroendocrine function. Science 292:107-110.

Tatar M., Bartke A., Antebi A. 2003. The endocrine regulation of aging by insulin-like signals. Science 299:1346-1351.

Tatar M., Yamamoto R., Flatt T., Dolezal A. 2010. Lifespan and reproduction regulation by juvenile hormone of adult Drosophila corpora allata (meeting abstract). Annual Drosophila Research Conference 51:115.

Tauber M. J., Tauber C. A., Masaki S. 1986. Seasonal Adaptations of Insects. New York: Oxford University Press.

Tauber E., Zordan M., Sandrelli F., Pegoraro M., Osterwalder N., Breda C., Daga A., Selmin A., Monger K., Benna C., Rosato E., Kyriacou C. P., Costa R. 2007. Natural selection favors a newly derived timeless allele in Drosophila melanogaster. Science 316:1895-1898.

Terada Y., Garofalo C. A., Sakagami S. F. 1975. Agesurvival curves for workers of two eusocial bees (Apis mellifera and Plebeia droryana) in a subtropical climate, with notes on worker polyethism in $P$. droryana. Journal of Apicultural Research 14:161-170.

Thoday J. M. 1972. Disruptive selection. Proceedings of the Royal Society of London B: Biological Sciences 182: 109-143.

Tollrian R., Harvell C. D. 1999. The Ecology and Evolution of Inducible Defenses. Princeton (New Jersey): Princeton University Press.

Tu M.-P., Yin C.-M., Tatar M. 2002. Impaired ovarian ecdysone synthesis of Drosophila melanogaster insulin receptor mutants. Aging Cell 1:158-160.

Tu M.-P., Yin C.-M., Tatar M. 2005. Mutations in insulin signaling pathway alter juvenile hormone synthesis in Drosophila melanogaster. General and Comparative Endocrinology 142:347-356. 
Tu M.-P., Flatt T., Tatar M. 2006. Juvenile and steroid hormones in Drosophila melanogaster longevity. Pages 415-448 in Handbook of the Biology of Aging, Sixth Edition, edited by E. J. Masoro and S. N. Austad. Burlington (Massachusetts): Academic Press (Elsevier).

Vanfleteren J. R., Braeckman B. P. 1999. Mechanisms of life span determination in Caenorhabditis elegans. Neurobiology of Aging 20:487-502.

Vanfleteren J. R., De Vreese A. 1995. The gerontogenes age-1 and daf-2 determine metabolic rate potential in aging Caenorhabditis elegans. FASEB Journal 9:1355-1361.

Vanfleteren J. R., De Vreese A. 1996. Rate of aerobic metabolism and superoxide production rate potential in the nematode Caenorhabditis elegans. Journal of Experimental Zoology 274:93-100.

Viney M. E., Gardner M. P., Jackson J. A. 2003. Variation in Caenorhabditis elegans dauer larva formation. Development, Growth Eं Differentiation 45:389-396.

Visscher P. K., Dukas R. 1997. Survivorship of foraging honey bees. Insectes Sociaux 44:1-5.

West-Eberhard M. J. 1989. Phenotypic plasticity and the origins of diversity. Annual Review of Ecology and Systematics 20:249-278.

West-Eberhard M. J. 2003. Developmental Plasticity and Evolution. Oxford (United Kingdom): Oxford University Press.

Wheeler D. E. 1986. Developmental and physiological determinants of caste in social Hymenoptera: evolutionary implications. American Naturalist 128:13-34.

Whitfield C. W., Behura S. K., Berlocher S. H., Clark A. G., Johnston J. S., Sheppard W. S., Smith D. R., Suarez A. V., Weaver D., Tsutsui N. D. 2006. Thrice out of
Africa: ancient and recent expansions of the honey bee, Apis mellifera. Science 314:642-645.

Williams G. C. 1957. Pleiotropy, natural selection, and the evolution of senescence. Evolution 11:398-411.

Williams K. D., Sokolowski M. B. 1993. Diapause in Drosophila melanogaster females: a genetic analysis. Heredity 71:312-317.

Williams K. D., Busto M., Suster M. L., So A. K.-C., Ben-Shahar Y., Leevers S. J., Sokolowski M. B. 2006. Natural variation in Drosophila melanogaster diapause due to the insulin-regulated PI3-kinase. Proceedings of the National Academy of Sciences of the United States of America 103:15911-15915.

Winston M. L. 1987. The Biology of the Honey Bee. Cambridge (Massachusetts): Harvard University Press.

Wollam J., Magner D. B., Magomedova L., Rass E., Shen Y., Rottiers V., Habermann B., Cummins C. L., Antebi A. 2012. A novel 3-hydroxysteroid dehydrogenase that regulates reproductive development and longevity. PLoS Biology 10:e1001305.

Wolkow C. A., Kimura K. D., Lee M.-S., Ruvkun G. 2000. Regulation of $C$. elegans life-span by insulinlike signaling in the nervous system. Science 290:147-150.

Zhao Z., Zera A. J. 2004a. A morph-specific daily cycle in the rate of $\mathrm{JH}$ biosynthesis underlies a morphspecific daily cycle in the hemolymph JH titer in a wing-polymorphic cricket. Journal of Insect Physiology 50:965-973.

Zhao Z., Zera A. J. 2004b. The hemolymph JH titer exhibits a large-amplitude, morph-dependent, diurnal cycle in the wing polymorphic cricket, Gryllus firmus. Journal of Insect Physiology 50:93-102.

Handling Editor: Daniel Dykhuizen 